\title{
The continued threat of emerging flaviviruses
}

\author{
Theodore C. Pierson ${ }^{1 凶}$ and Michael S. Diamond $\oplus^{2 \bowtie}$
}

\begin{abstract}
Flaviviruses are vector-borne RNA viruses that can emerge unexpectedly in human populations and cause a spectrum of potentially severe diseases including hepatitis, vascular shock syndrome, encephalitis, acute flaccid paralysis, congenital abnormalities and fetal death. This epidemiological pattern has occurred numerous times during the last $\mathbf{7 0}$ years, including epidemics of dengue virus and West Nile virus, and the most recent explosive epidemic of Zika virus in the Americas. Flaviviruses are now globally distributed and infect up to $\mathbf{4 0 0}$ million people annually. Of significant concern, outbreaks of other less well-characterized flaviviruses have been reported in humans and animals in different regions of the world. The potential for these viruses to sustain epidemic transmission among humans is poorly understood. In this Review, we discuss the basic biology of flaviviruses, their infectious cycles, the diseases they cause and underlying host immune responses to infection. We describe flaviviruses that represent an established ongoing threat to global health and those that have recently emerged in new populations to cause significant disease. We also provide examples of lesser-known flaviviruses that circulate in restricted areas of the world but have the potential to emerge more broadly in human populations. Finally, we discuss how an understanding of the epidemiology, biology, structure and immunity of flaviviruses can inform the rapid development of countermeasures to treat or prevent human infections as they emerge.
\end{abstract}

F laviviruses are single-stranded RNA viruses vectored principally by arthropods that cause severe illnesses in humans. The extensive global spread and epidemic transmission of flaviviruses during the last seven decades has been remarkable. The mosquito-borne dengue viruses (DENV) infect an estimated 400 million humans each year; more than a quarter of the world's population lives in areas where DENV is now endemic ${ }^{1}$. By comparison, only sporadic DENV epidemics were documented before the Second World War'. The introductions of West Nile (WNV) and Zika (ZIKV) viruses into the Western Hemisphere was followed by rapid geographical spread, large numbers of human infections and considerable morbidity ${ }^{3,4}$. Ongoing yellow fever virus (YFV) transmission and its encroachment on urban environments, despite the existence of an effective vaccine, poses a serious public health challenge ${ }^{5-7}$. Other flaviviruses present ongoing health risks or are beginning to emerge in different parts of the world, including Japanese encephalitis virus (JEV), tick-borne encephalitis virus (TBEV) and Usutu virus (USUV).

The epidemic potential of flaviviruses reflects many factors related to the unique characteristics of their insect vectors, the consequences of poorly planned urbanization that creates ideal arthropod breeding habitats, the geographical expansion of vectors, changing environmental conditions and extensive global travel ${ }^{8,9}$. Beyond arthropods and humans, flaviviruses are also known to infect a wide array of animal species and can be important veterinary pathogens that threaten economically important domesticated animals ${ }^{10-14}$. These vertebrate animal hosts may constitute important stable reservoirs and contribute to defining conditions that support the introduction of new viral species and transmission among humans ${ }^{15}$. The continued threat of flavivirus emergence and re-emergence highlights a need for a detailed fundamental understanding of the biology of these viruses, the immune responses that can contain them and the possible countermeasures that can blunt their impact on public health should new outbreaks occur.

\section{Flavivirus structure and replication}

Flaviviruses are small $(\sim 50 \mathrm{~nm})$ spherical virus particles that incorporate a single genomic RNA of positive-sense polarity encoding three structural and seven non-structural proteins (Fig. 1a). Our knowledge of the biology of flaviviruses has advanced considerably with the availability of high-resolution structures of viral structural proteins and of virions at different stages of the replication cycle or in complex with antibodies or host factors ${ }^{16}$. Crystal structures of the enzymatic non-structural proteins also have been solved, accelerating advances in an understanding of virus replication and pathogenesis ${ }^{17-19}$ and enabling structure-guided drug discovery, as reviewed elsewhere ${ }^{20}$.

Virion structure and morphogenesis. Flaviviruses are assembled using three viral structural proteins (C, prM and E), a host lipid envelope and the viral genomic RNA. The structure of the envelope (E) protein, which mediates virus entry steps of the replication cycle, was solved first for $\mathrm{TBEV}^{21}$ and thereafter for multiple flaviviruses including DENV, WNV and ZIKV (reviewed in ref. ${ }^{22}$ ). The E protein is a three-domain structure (referred to as domains E-DI, E-DII and E-DIII) tethered to the viral membrane by a helical stem and two antiparallel transmembrane domains (Fig. 1b). Most flavivirus E proteins are modified post-translationally by the addition of one or two asparagine-linked carbohydrates. The folding of the $\mathrm{E}$ protein in the endoplasmic reticulum (ER) is facilitated by interactions with the structural premembrane (prM) protein shortly after synthesi ${ }^{23}$. prM is incorporated into the viral envelope during virion morphogenesis as heterotrimeric prM-E spikes with icosahedral symme$\operatorname{try}^{24}$ (Fig. 1c) and prevents conformational changes in the $\mathrm{E}$ protein that would allow adventitious fusion of virions with host membranes during egress. Cleavage of prM to $\mathrm{M}$ during transit of immature virions through the trans-Golgi network by a host furin-like serine protease is required for the formation of infectious mature forms of the virion ${ }^{25}$. On mature virions, E proteins are arranged as antiparallel dimers via extensive contacts between adjacent

'Laboratory of Viral Diseases, National Institute of Allergy and Infectious Diseases, the National Institutes of Health, Bethesda, MD, USA. ${ }^{2}$ Departments of Medicine, Molecular Microbiology, Pathology \& Immunology, Andrew M. and Jane M. Bursky Center for Human Immunology and Immunotherapy Programs, Washington University School of Medicine, St. Louis, MO, USA.凶e-mail: piersontc@mail.nih.gov; diamond@wusm.wustl.edu 
a

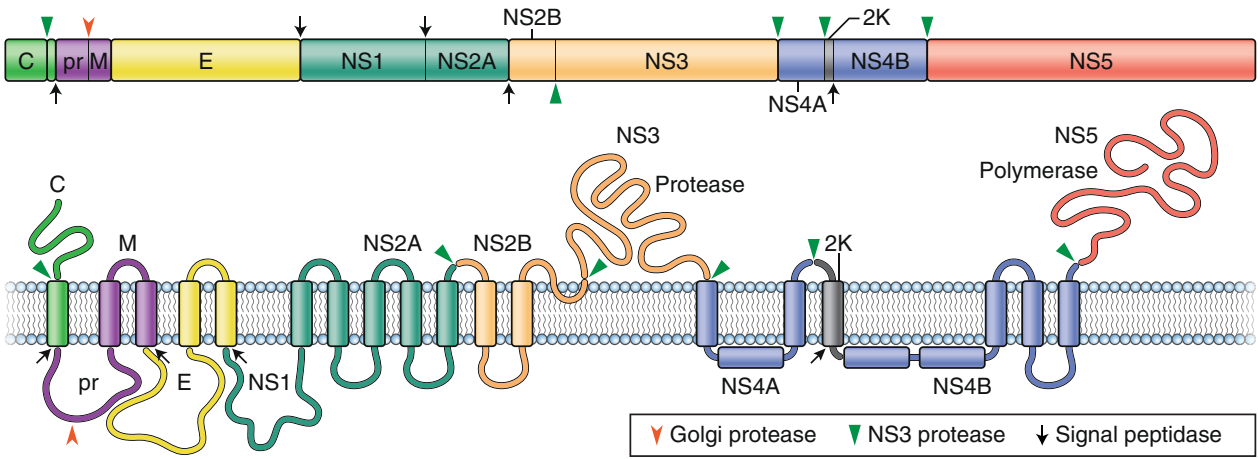

b

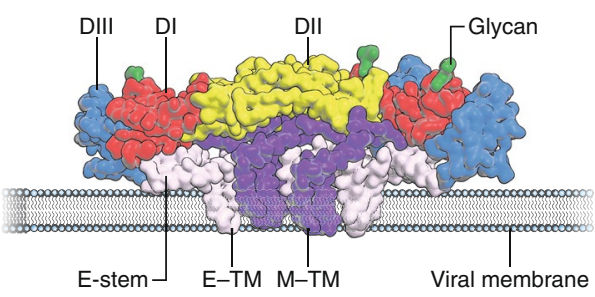

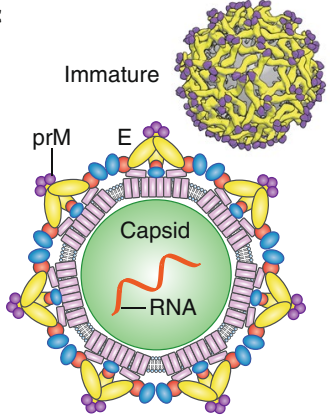

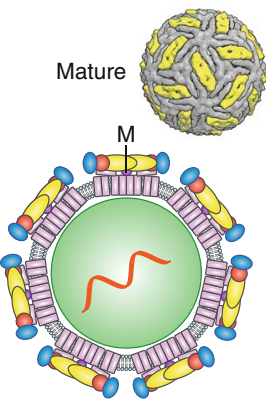

Fig. 1 | Organization and structure of flaviviruses. a, Flaviviruses encode a single open reading frame that is translated at the ER into a polyprotein, which is subsequently cleaved by viral and host cell proteases. This processing results in ten functional proteins including the three structural proteins, $\mathrm{C}$, prM and $\mathrm{E}$, and seven non-structural proteins. NS4A exists in two forms that differ with respect to cleavage of the $2 \mathrm{~K}$ domain at its carboxy terminus. b. Flavivirus $E$ proteins are elongated three-domain structures tethered to the viral membrane by a stem and two antiparallel transmembrane domains. E protein domains are indicated in red, yellow and blue (DI-III, respectively). The M protein, also attached to the viral membrane by two transmembrane domains, is shown in purple. c, The distinct arrangement of E proteins on immature (left) and mature (right) forms of the virion are depicted. Image courtesy of Ethan Tyler.

E-DIIs ${ }^{26-29}$. Ninety $\mathrm{E}$ dimers are incorporated into each mature virion and arranged in a herringbone pattern with icosahedral-like symmetry (Fig. 1c). The viral capsid (C) protein is a small helical protein with surfaces that bind either viral nucleic acids or host lipids and directs the incorporation of the viral genome into the virion ${ }^{30}$. Establishing the physical connection between membrane-anchored structural proteins and the $\mathrm{C}$ protein or RNA has been elusive. The application of asymmetric reconstruction techniques to the cryo-electron microscopy (cryo-EM) analysis of ZIKV provides evidence that the capsid interacts transiently with the other structural proteins during particle biogenesis ${ }^{31}$. C-protein incorporation into the virion is regulated further by the coordinated cleavage of the polyprotein by the viral non-structural protein 2B (NS2B)-NS3 serine protease $\mathrm{e}^{32}$.

Flavivirus entry. Flaviviruses bind to an array of mammalian cell types through interactions of asparagine-linked sugars on structural proteins with multiple C-type lectins including dendriticcell-specific intercellular adhesion molecule-3-grabbing nonintegrin (DC-SIGN) ${ }^{33,34}$, the binding of charged surfaces of the E protein to glycosaminoglycans on cell surfaces ${ }^{35}$ and interactions between the viral lipid envelope and proteins of the T-cell immunoglobulin domain and mucin domain (TIM) and Tyro3, Axl and Mertk (TAM) family of phosphatidylserine receptors ${ }^{36}$ (Fig. 2). The role of specific host proteins in the attachment and entry of viruses into cells varies. Host proteins classically defined as receptors are essential for the entry of viruses because they catalyse critical conformational events. For example, the CD4 molecule on $\mathrm{T}$ lymphocytes enables conformational transitions in the human immunodeficiency virus type 1 GP120 protein required for viral membrane fusion ${ }^{14}$. While host factors that increase the efficiency of flavivirus binding and infection of cells have been identified, they are not required to trigger the structural transitions that propel viral membrane fusion; instead, these are defined as attachment factors. Flaviviruses bound to synthetic lipid membranes devoid of host proteins are capable of stimulating E protein-mediated fusion once exposed to an acidic environment ${ }^{37,38}$. Identifying virus-host receptor interactions important for pathogenesis in humans and other vertebrate animals has been challenging, and even less is known about entry pathways in invertebrate host cells. Relationships between host attachment factor expression and viral tropism in vivo have not been established. Some flavivirus attachment factors (for example, TAM and integrin receptors) capable of binding virions also transduce signals into target cells, which has the potential to augment infection and further complicates the role and definition of host attachment molecules ${ }^{39-42}$.

Once attached to cells, flaviviruses are taken up by clathrindependent endocytic vesicles. While this same host machinery is involved in the internalization of multiple types of cellular cargo, recent studies identified host molecules required by flaviviruses to exploit the endocytic pathway for infectious entry including RNASEK, lymphocyte antigen locus 6 (LY6E) and microtubules ${ }^{43-45}$. Flavivirus membrane fusion occurs in the low $\mathrm{pH}$ compartments of the endosome and is catalysed by conformational changes in the E protein that involve the formation of $\mathrm{E}$ protein trimers, penetration of the highly conserved E-DII fusion loop into the adjacent host membranes and the folding of the E protein helical stem against the exterior surface of the newly formed E protein trimer ${ }^{46}$. A structural and kinetic understanding of flavivirus membrane fusion has informed the design of antiviral molecules that disrupt the entry process $^{47}$ (Fig. 2). 


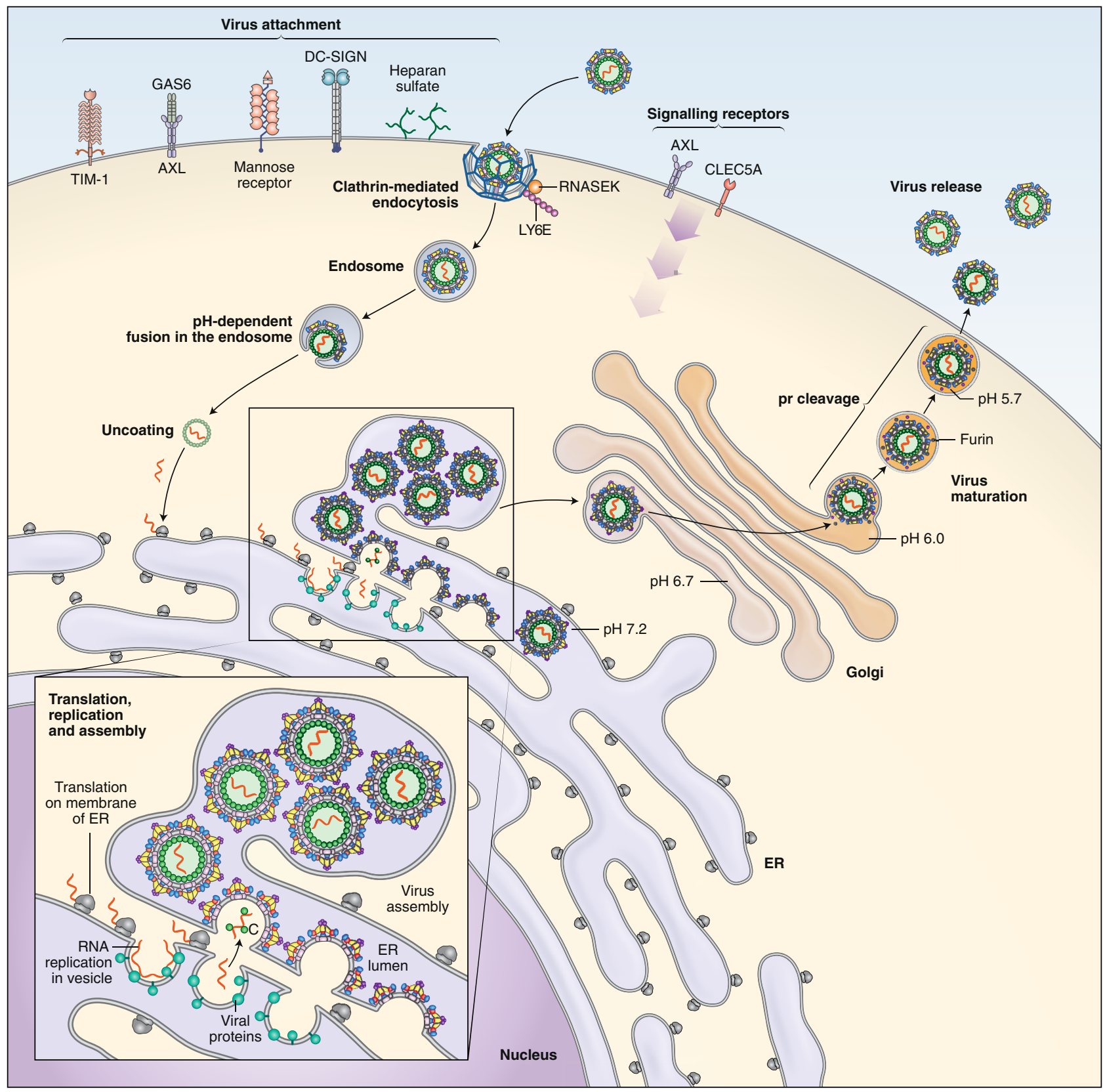

Fig. 2 | The flavivirus replication cycle. Flaviviruses infect mammalian cells via interactions with multiple types of host attachment factors, including molecules that bind to the viral membrane or virion-associated N-linked carbohydrates. Interactions with cell-surface host factors, such as C-type lectin member 5A (CLEC5A), may also initiate signalling pathways that modulate the host immune response. Virions are internalized by clathrin-dependent mechanisms that usurp host factors involved in the uptake of large macromolecules, including RNASEK. Viral fusion with host membranes occurs in the endosome in a low pH-dependent manner. Viral RNA replication occurs on membranes of the host reorganized through the actions of the non-structural proteins. These virus-induced membrane structures spatially coordinate viral genomic RNA replication and virion morphogenesis, and shield replication products from host innate immune sensors. Virus particles assemble at and bud into the ER and traffic out of the cell. Virion maturation, defined by the cleavage of prM by a furin-like protease, occurs during egress. GAS6, growth arrest-specific protein 6. Image courtesy of Ethan Tyler.

Flavivirus replication. The flavivirus genomic RNA encodes a single open reading frame flanked by highly structured untranslated regions (UTR) that coordinate viral translation, replication and regulation of the innate immune response $\mathrm{e}^{48}$. The penetration of the viral genome into the cytoplasm allows for the cap-dependent translation of the viral polyprotein in association with membranes of the $\mathrm{ER}^{49}$. Viral translation products are believed to stimulate a shift in the use of the incoming viral genome from a substrate for translation to a template for genomic RNA replication. Flavivirus replication occurs on complex virus-induced membrane structures incorporating host and viral factors ${ }^{50}$. The ultrastructure of these flavivirus replication complexes (RCs) was solved using cryo-EM tomography, revealing invaginations of the ER that form spherical compartments in which viral components required for RNA replication can be located, including NS1, NS2A, NS3, NS4A and NS5 (refs. ${ }^{50,51}$ ) (Fig. 2). Although the contents of these vesicle packets are protected from surveillance by cytoplasmic innate immune sensors, narrow connections exist to allow movement of viral RNA replication products to sites of translation and virion morphogenesis. Changes in host cell metabolism are important for 


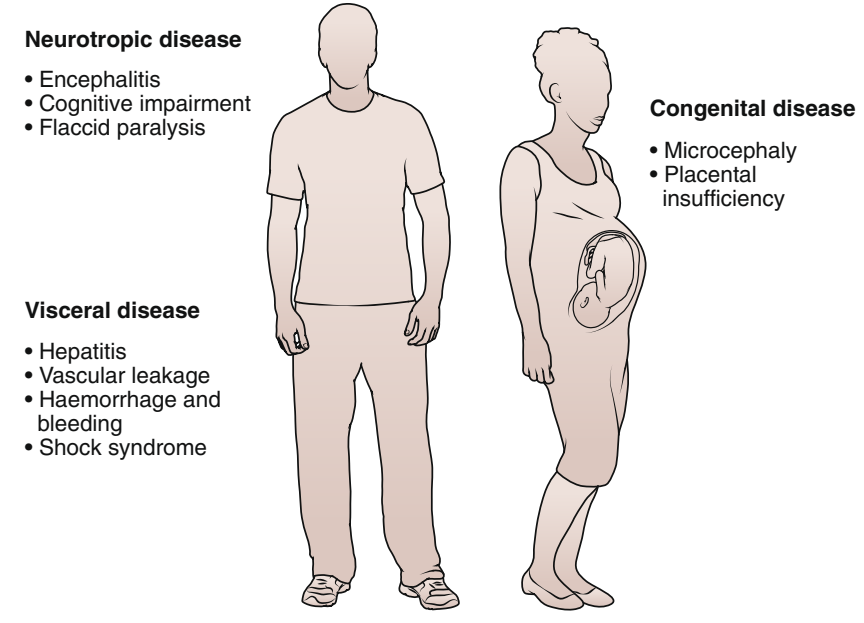

Fig. 3 | Disease syndromes of flavivirus infection. Flaviviruses cause different febrile syndromes depending on the virus and the affected patient. Several flaviviruses are neurotropic (for example, WNV, JEV, TBEV, USUV, ZIKV and ILHV), can spread to the brain and spinal cord and cause severe neurological syndromes including meningitis, encephalitis and acute flaccid paralysis. These can result in death or long-term disability in survivors. Other flaviviruses (such as YFV, DENV and ZIKV) cause visceral disease resulting in liver failure, haemorrhagic syndromes and vascular compromise, and can also result in death. Uniquely, ZIKV can infect the tissues of the male and female reproductive tracts leading to sexual transmission. ZIKV infection during pregnancy can cause injury to the placenta and can transmit to the developing fetus, resulting in placental insufficiency, microcephaly, congenital malformations and fetal demise. Image courtesy of Ethan Tyler.

the generation of RCs, including an increase in cholesterol, fatty acid and sphingomyelin synthesis; regulation of autophagy also has been suggested to contribute to virus-induced changes in lipid metabolism ${ }^{52,53}$. Host factors such as the reticulon protein $3.1 \mathrm{~A}$ and DNAJC14 also are critical for RC formation ${ }^{54,55}$. As many of the enzymes involved in these metabolic changes are targets for therapeutics, a more detailed understanding of the host pathways and networks required to support flavivirus replication may identify new classes of antiviral agents ${ }^{56}$.

\section{Flavivirus-induced disease}

The clinical presentation of acute flavivirus infection in humans ranges from mild illness (asymptomatic infection or self-limiting febrile episodes) to severe and life-threatening disease (haemorrhagic fever, shock syndrome, encephalitis, paralysis, congenital defects, hepatitis and hepatic failure). Individual flavivirus infections fall into two broad categories, visceral and neurotropic, although some have features of both (for example, ZIKV) (Fig. 3). Variability in disease presentation among individual flaviviruses likely reflects the unique cellular and tissue tropism of each virus, differences in their capacity to evade or antagonize host immunity, and the interplay between the direct pathogenic effects of virus infection and injury caused by the requisite host response. Approximately $50-80 \%$ of flavivirus infections are asymptomatic and cause little to no illness ${ }^{57-59}$. Most symptomatic flavivirus infections result in self-limiting flu-like febrile illnesses with a headache, myalgia, arthralgia and a rash without long-term consequences. The factors that determine the penetrance of more severe disease phenotypes for different flaviviruses are not fully characterized, but likely reflect polymorphisms in key host genes (for example, CCR5 for $\mathrm{WNV}^{60}$, DC-SIGN for $\left.\mathrm{DENV}^{61}\right)$, age ${ }^{62}$, immune status and co-morbidities, and prior flavivirus immunity (for example, $\mathrm{DENV}^{63}$ ), in addition to differential pathogenicity of particular virus strains and perhaps other acquired factors including the microbiome ${ }^{64}$.

Visceral disease. DENV, YFV and ZIKV are the principal flaviviruses that cause visceral disease in humans. DENV infection of myeloid cells in blood and tissues is believed to induce an immunopathogenesis cascade resulting in vascular leakage, thrombocytopenia, abnormal bleeding, haemoconcentration and hypotension ${ }^{65,66}$. The flavivirus NS1 protein may contribute to hypotension by virtue of its ability to bind endothelial cells, disrupt the integrity of underlying glycocalyx and alter vascular permeability ${ }^{67,68}$. YFV replicates to high levels in liver cells, and this results in severe hepatitis, renal failure, haemorrhage, shock and death ${ }^{69,70}$. ZIKV infects progenitor cells, epithelium and myeloid cells, and in peripheral tissues causes injury to the male and female reproductive tracts and the eye $\mathrm{e}^{71}$. ZIKV persists in human semen for months ${ }^{72}$ and may cause oligospermia, lower levels of sex hormones and, possibly, compromised fertility $^{73}$. The high viral load in seminal fluid also can lead to sexual transmission of $\mathrm{ZIKV}^{74}$.

Neurotropic disease. WNV, JEV, TBEV, Powassan virus (POWV) and ZIKV are neurotropic viruses that can cause encephalitis, cognitive impairment, seizure disorders and paralysis ${ }^{75}$. The neurological and functional disability associated with these neurotropic flavivirus infections can cause considerable morbidity in patients long after their recovery from acute illness. These viruses cause injury to neurons (or neuroprogenitor cells in the case of ZIKV) through direct (virus infection-induced) and indirect (immune-mediated) mechanisms ${ }^{75,76}$. Microscopic examination of the brain reveals neuronal cell death, activation of microglia and infiltrating macrophages, and accumulation of $\mathrm{CD}^{+}$and $\mathrm{CD}^{+} \mathrm{T}$ cells. Depending on the flavivirus, these lesions can occur in the brainstem, cerebral cortex, hippocampus, thalamus, cerebellum or spinal $\operatorname{cord}^{77}$.

Congenital disease. As well as being neurotropic, ZIKV is also teratogenic, in part because it infects and causes injury to the developing placenta ${ }^{78}$. The tropism of ZIKV for the placenta ${ }^{71}$ may not be unique among flaviviruses, as inoculation of human placental explants or pregnant mice with WNV or POWV also resulted in infection and injury to the placenta ${ }^{79}$.

\section{Immune response to flavivirus infection}

In this section, we highlight recent advances relating to cell-intrinsic host defence activation, and innate and adaptive immune response-dependent restriction of flavivirus infections. We discuss how these findings affect the development of candidate therapeutics.

Innate immunity. The mammalian host detects and responds to flavivirus infection by recognizing viral RNA through several pathogen recognition receptors (PRRs), including the cell surface and endosomal RNA sensors Toll-like receptors 3 and 7, the cytoplasmic RNA sensors retinoic acid-inducible gene I (RIG-I) and melanoma-differentiation-associated gene 5 (ref. ${ }^{80,81}$ ). Binding of single- and/or double-stranded viral RNA results in the downstream activation of adaptor molecules, such as mitochondrial antiviral signalling protein, MyD88, TIR domain-containing adaptor inducing IFN- $\beta$ (TRIF), nuclear translocation of interferon (IFN) regulatory transcription factors 3 and 7 (IRF3 and IRF7) and NF- $\mathrm{B}$, which induce expression of type I and III IFNs. The cytoplasmic adaptor molecule stimulator of IFN genes (STING) also participates in immune responses generated against flaviviruses in the context of RIG-I recognition, by acting as a scaffold for the recruitment of signalling components required for IRF3 activation and IFN induction ${ }^{82-84}$.

Type I interferons (IFN- $\alpha$ and $\beta$ ) promote an antiviral state by inducing IFN-stimulated genes (ISGs) with direct and indirect 
antiviral functions (reviewed in refs. ${ }^{85,86}$ ). Pre-treatment of cells with type I IFNs inhibits flavivirus replication in vitro, but treatment after infection is less effective. Although flaviviruses can antagonize IFN-induced responses after infection by preventing induction of IFNs and disrupting their signalling pathways ${ }^{87}$, IFN still restricts replication and spread in vivo. Mice lacking the type I IFN receptor (Ifnar $1^{-/}$) show expanded tropism and greater morbidity and mortality than wild-type mice after infection with multiple different flaviviruse ${ }^{88,89}$. Type III IFN $-\lambda$ is an antiviral cytokine that binds a unique receptor and primarily functions at barrier surfaces ${ }^{90}$. In cell culture, IFN- $\lambda$ has direct antiviral effects against flaviviruses through induction of ISGs ${ }^{91,92}$. IFN- $\lambda$ also has inhibitory activity against ZIKV in the context of infection of the maternal-derived decidua and fetal-derived placenta during pregnancy in mice and humans ${ }^{93-95}$.

Some of the recently identified ISGs that display antiviral activity against flaviviruses ${ }^{85}$ in vitro include: C6orf150, DDX24, HPSE, MAFK, NAMPT, PAK3, PHF15, SAMD9L, SC4MOL, C19orf66, CH25H, IFI44L, IFIT1, IFIT2, IFI6, IFITM2, IFITM3, ISG20 and $R S A D 2$ (viperin). ISGs with demonstrated antiviral activity against flaviviruses in vivo include: PKR, RNASEL, RSAD2, IFIT1, IFIT2, IFITM3, Ifi27l2a and $\mathrm{CH}_{2} 5 \mathrm{H}^{96-99}$. The inhibitory mechanisms of some well-described ISGs have been reviewed ${ }^{98,100}$, with some targeting flavivirus entry and/or fusion (IFITM3 and $\mathrm{CH} 25 \mathrm{H}$ ), translation (IFIT1/2, PKR and C19orf66) or replication (RNASEL and RSAD2). However, the mechanisms by which many other ISGs restrict flavivirus infections remain to be determined. Further delineation of how specific ISGs restrict flaviviruses could create opportunities for pharmacological targeting and enhanced resistance to infection.

B-cell immunity. The importance of antiviral antibodies against flaviviruses is well-established ${ }^{101}$. Passive transfer of virus-reactive monoclonal or polyclonal antibodies confers significant protection in animal models ${ }^{102,103}$. Anti-flavivirus antibodies may also exert protective effects via effector functions mediated by the Fc portion of the antibody molecule, including complement fixation, antibody-mediated cellular cytotoxicity and antibody-mediated opsonization, all of which can facilitate viral clearance ${ }^{104,105}$. Protective antibodies against flaviviruses predominantly recognize epitopes on the E protein of the virion, but also can bind to regions of the cell surface and secreted forms of NS1 (refs. ${ }^{106,107}$ ).

Neutralizing anti-flavivirus antibodies can inhibit infection at multiple steps in the virus lifecycle, including a blockade of virus attachment to host cells ${ }^{108}$, presumably by disrupting interactions with attachment factors or receptors. Flavivirus-reactive antibodies may also block infection after the attachment step. Many potently neutralizing and protective antibodies inhibit the $\mathrm{pH}$-dependent structural changes required for endosomal fusion and nucleocapsid release $\mathrm{e}^{109}$. In contrast, some flavivirus-reactive antibodies increase the efficiency of infection under certain conditions. Such antibody-dependent enhancement (ADE) of infection occurs when non-neutralizing amounts of antibody bind virions and promote more efficient infection of cells expressing activating $\mathrm{Fc}-\gamma$ receptors via enhancement of virion attachment and internalization ${ }^{110}$. While readily demonstrated in vitro with multiple flaviviruses using cell lines or primary $\mathrm{Fc}-\boldsymbol{\gamma}$-expressing cells, a role for $\mathrm{ADE}$ in vivo has only been demonstrated convincingly for $\mathrm{DENV}^{111,112}$.

T-cell immunity. Studies have established important roles for both $\mathrm{CD}^{+}$and $\mathrm{CD}^{+} \mathrm{T}$ cells in flavivirus pathogenesis and immunity (reviewed in refs. ${ }^{107,113,114}$ ). The protective roles of $\mathrm{CD} 4^{+} \mathrm{T}$ cells may differ during primary and memory responses. In mice, $\mathrm{CD} 4^{+} \mathrm{T}$ cells control primary WNV, YFV, ZIKV and JEV infection and disease ${ }^{115}$. In comparison, $\mathrm{CD}^{+} \mathrm{T}$ cells were not required for controlling primary DENV infection, yet instead contributed to viral clearance after immunization and challenge ${ }^{116}$. $\mathrm{CD} 4^{+} \mathrm{T}$ cells can also protect against flavivirus infection by providing help for antibody responses, sustaining $\mathrm{CD}^{+} \mathrm{T}$-cell responses that enable viral clearance, producing antiviral cytokines and lysing some infected cell targets. In humans, impaired JEV-specific $\mathrm{CD} 4^{+} \mathrm{T}$-cell function was seen preferentially in patients with encephalitis and neurological sequelae ${ }^{117}$. As DENV-specific CD4 ${ }^{+} \mathrm{T}$ cells show cytolytic activity ex vivo and are associated with a protective class II major histocompatibility complex allele, they are believed to control DENV infection in humans ${ }^{118}$.

Memory $\mathrm{CD}^{+} \mathrm{T}$ cells can have protective or pathological consequences depending on the context. For DENV, immunization schemes that elicited antigen-specific $\mathrm{CD} 4^{+} \mathrm{T}$ cells prior to infection of mice resulted in diminished viral burden after challenge with homologous DENV ${ }^{116}$. Memory T-cell responses elicited by prior infection with DENV recognize ZIKV-derived peptides and influence the magnitude and quality of the ZIKV T-cell response ${ }^{119}$. Although cross-reactive $\mathrm{CD} 4^{+} \mathrm{T}$ cells against conserved peptides can be detected across flaviviruses, their effect on viral infection and disease remains uncertain. In some settings, the memory response may also have pathological consequences. For example, $\mathrm{CD}^{+} \mathrm{T}$ cells primed against one serotype of DENV can result in the over-exuberant production of inflammatory cytokines and an increased risk for severe disease in the context of infection with a second, heterologous DENV serotype ${ }^{120}$.

$\mathrm{CD}^{+} \mathrm{T}$ cells, by virtue of their ability to lyse infected target cells and produce pro-inflammatory cytokines, can also have protective or pathological effects against flaviviruses depending on the context. In mice, $\mathrm{CD}^{+} \mathrm{T}$ cells can be an essential component of protection against and for the resolution of primary infection by several different flaviviruses (such as WNV, ZIKV and DENV) ${ }^{121-123}$. Flavivirus-specific cytotoxic $\mathrm{CD} 8^{+} \mathrm{T}$ cells proliferate, release proinflammatory cytokines including IFN- $\gamma$ and tumour necrosis factor (TNF), and lyse cells through the delivery of perforin and granzymes, or via Fas-Fas ligand or TNF-related apoptosis-inducing ligand (TRAIL) interactions ${ }^{113}$. Consequently, mice deficient in these molecules had increased viral burden ${ }^{124,125}$. Heterologous, memory T-cell responses also can have protective functions, as cross-reactive DENV-immune $\mathrm{CD} 8^{+} \mathrm{T}$ cells restrict ZIKV infection and disease, including in pregnancy ${ }^{126,127}$. Reciprocally, ZIKV-immune $\mathrm{CD}^{+}$ $\mathrm{T}$ cells can protect against DENV infection in mice ${ }^{128}$.

In certain circumstances, flavivirus-specific $\mathrm{CD}^{+} \mathrm{T}$ cells can cause immunopathology. The antiviral activity of $\mathrm{CD}^{+} \mathrm{T}$ cells within the brain markedly limited ZIKV infection of neurons, but also triggered ZIKV-associated paralysis in mice ${ }^{129}$. $\mathrm{CD}^{+}$ $\mathrm{T}$ cells induced immunopathology in the brain after infection with $\mathrm{TBEV}^{130}$, and for DENV, a pathogenic role of $\mathrm{CD}^{+} \mathrm{T}$ cells has been described during secondary infection. Serotype cross-reactive $\mathrm{CD}^{+} \mathrm{T}$ cells are preferentially activated during secondary infection in humans ${ }^{131}$ and exhibit altered cytokine production and reduced cytolytic activity ${ }^{132,133}$. Aberrant cytokine production by $\mathrm{CD}^{+} \mathrm{T}$ cells could contribute to severe DENV disease by promoting endothelial cell dysfunction or damage and plasma leakage ${ }^{134}$. Notwithstanding these data, other human studies suggest that CD8 ${ }^{+}$ $\mathrm{T}$ cell responses, in the context of secondary DENV infection, may have beneficial consequences ${ }^{114,135}$.

Given this background on how flaviviruses replicate, are recognized by the host immune system and the clinical diseases they cause, in the next sections we will describe the flaviviruses that are considered established threats, those that have recently emerged as global health threats and, finally, those which may emerge to cause future epidemics.

\section{Established threats}

Dengue virus. After mosquito inoculation, the four serotypes of DENV can cause human clinical disease ranging from self-limited 
dengue fever to a life-threatening syndrome, termed 'severe dengue'. DENV now causes an estimated 390 million total infections, 100 million clinically apparent cases and 500,000 presentations of severe dengue per year worldwide, with at least 2.5 billion people at risk ${ }^{1}$ (Table 1). Over the past 70 years, the number of people infected has risen steadily, making DENV the most prevalent arthropod-borne viral disease in the world. Severe dengue routinely occurs in more than 100 countries, including those in the Americas, Asia, Africa and Australia; in essence, wherever the primary mosquito vector Aedes aegypti is present (Fig. 4). In the continental United States, although some regions (the Gulf Coast and the south east) periodically experience dengue outbreaks ${ }^{136,137}$, sustained transmission has not occurred recently, possibly due to indoor lifestyles and rapid mosquito control efforts (such as spraying and larvicide strategies) implemented once DENV cases are detected.

The incidence of severe dengue varies between primary and secondary infections. A secondary DENV infection results when a person previously infected with one serotype is exposed to a different serotype, and is the single most important risk factor for severe dengue disease $\mathrm{e}^{138,139}$. Severe dengue is characterized by rapid onset of capillary leakage accompanied by thrombocytopenia and mild to moderate liver damage ${ }^{140}$. Although haemorrhagic manifestations occur (for example, epistaxis, gastrointestinal tract bleeding and menorrhagia), fluid loss into tissue spaces and the resulting hypotension carries the greatest risk of mortality ${ }^{141}$. Whereas severe dengue occurs principally after secondary infection in children and adults $^{142}$, in infants under the age of one born to dengue-immune mothers, a primary DENV infection can cause substantial morbidity and mortality ${ }^{143}$. Maternal anti-dengue antibody titers and the age of the infant correlated with disease. Severe dengue often occurs in infants (peaking at 7 months of age) when maternal serum antibodies wane and enhance rather than neutralize infection of monocytes via $\mathrm{ADE}^{112}$. Severe dengue is more prevalent in infants ${ }^{144}$ and has a higher mortality rate compared to other age groups ${ }^{145}$.

West Nile virus. WNV, which was first isolated in 1937 (ref. ${ }^{146}$ ), cycles in nature between Culex mosquitoes and birds but also infects and causes disease in humans, horses and other mammals (Table 1). Although its enzootic cycle is between mosquitoes and birds, with mammals serving as 'dead-end' hosts because of low-level and transient viraemia, non-viraemic transmission of WNV between co-feeding mosquitoes suggests that some mammals could act as additional reservoirs ${ }^{147}$. Historically, WNV caused sporadic outbreaks of a febrile illness in regions of Africa, the Middle East, Asia and Australia that were not associated with severe human disease. However, in the 1990s, the epidemiology of infection changed. Cases in Eastern Europe were associated with neurological disease ${ }^{148}$. In 1999, WNV entered North America and caused seven human fatalities in the New York area as well a large number of avian and equine deaths. In the United States, some avian species were particularly vulnerable, with a large number of deaths in crows, jays and hawks recorded during the epidemic. Over the past two decades, WNV has spread to and circulated in continental United States as well in Canada, Mexico, the Caribbean and South America (Fig. 4). Because of the increased range, the number of human cases has continued to rise: in the United States, 51,747 cases were confirmed between 1999-2019. Forty-eight percent of these cases caused acute flaccid paralysis, meningitis and/or encephalitis and were associated with 2,381 deaths ${ }^{149}$. Based on blood supply screening, 2,000,000 to 4,000,000 total infections likely occurred in the United States between 1999 and $2010\left(\right.$ ref. ${ }^{150}$ ). Moreover, WNV continues to emerge in parts of Eastern Europe ${ }^{151}$ with severe neurological disease and fatalities caused by a different genetic lineage, termed lineage $2 \mathrm{WNV}^{152}$. In 2018, an unusually high number of infections in horses and people were reported in southern parts of Europe $^{153}$. Although sequence determinants responsible for greater virulence in birds have been identified (for example, a T249P amino acid substitution in NS3 (ref. ${ }^{154}$ )), the basis for enhanced pathogenicity of contemporary American and European isolates in humans remains an unanswered question.

Japanese encephalitis virus. JEV causes severe neurological disease and is primarily prevalent in Asia, where it accounts for $\sim 35,000$ to 50,000 cases and 10,000 to 15,000 deaths annually ${ }^{155}$. JEV epidemics were originally described in Japan in the nineteenth century, and the virus was first recovered in 1935 from an infected human in Tokyo. While the majority of human infections are asymptomatic, many symptomatic cases result in meningitis, encephalitis and/ or flaccid paralysis, and are fatal or cause devastating long-term neurological sequelae ${ }^{156}$ (Table 1). In one study of children with JEV encephalitis ${ }^{157}$, only $44 \%$ of patients recovered fully, with $8 \%$ dying during the acute phase and $31 \%$ having persistent neurological, developmental and psychiatric disease. The enzootic cycle of JEV is between water birds and Culex mosquitoes, with pigs also serving as an amplifying host. Humans are considered incidental dead-end hosts and generally do not produce viraemia sufficient to infect mosquitoes. Despite the introduction of inactivated and live-attenuated vaccines ${ }^{158}$, JEV remains an important global cause of viral encephalitis. JEV is classified into a single serotype with five genotypes, and infection and disease occur across a large range of Asian countries with outbreaks occurring in Japan, China, Taiwan, Korea, the Philippines, India and the eastern region of Russia (Fig. 4). Epidemic activity in India, Nepal and other parts of Southeast Asia appears to be escalating, and JEV more recently has been described in Pakistan, Papua New Guinea and Australia, suggesting that its geographic range may be expanding ${ }^{159}$. Indeed, autochthonous transmission of JEV was detected for the first time in Africa in a febrile patient from Angola ${ }^{160}$. Of concern, the more divergent genotype $\mathrm{V}$ strains (amino acid divergence from $8.4 \%$ to $10.0 \%$ compared to genotypes I-IV) have been detected in Malaysia ${ }^{161}$, Korea $^{162}$ and China ${ }^{163}$, and may be covered poorly by existing genotype III-based vaccines. Currently, approximately 50 percent of the world's population is living in regions that are endemic to $\mathrm{JEV}^{164}$. There is also concern that JEV could spread to the Americas, much like WNV did, since North American field-collected Culex mosquitoes are susceptible to JEV infection ${ }^{165}$, and several avian species in North America are susceptible to JEV and can potentially serve as amplification hosts.

\section{Emerging and re-emerging threats}

Yellow fever virus. YFV is the prototype and namesake of the flavivirus genus owing to the jaundice that characterizes severe infections. While most infections are asymptomatic, YFV causes an acute febrile illness that may result in hepatitis, renal failure, haemorrhage and $\operatorname{shock}^{70,166}$ (Table 1). Infection is fatal in $20-60 \%$ of severe symptomatic cases ${ }^{167}$. Trade between Africa, where YFV is thought to have originated, and the New World or Europe drove devastating outbreaks in coastal cities during the eighteenth and nineteenth century that shaped the development and economies of the Americas ${ }^{168}$. These outbreaks ultimately were blunted by the deployment of a vaccine and measures to control mosquito populations.

Despite the existence of an effective vaccine, YFV remains endemic in many parts of the world (Fig. 4$)^{169,170}$. YFV has an equatorial distribution across the African continent, bounded in the north by the Sahara Desert and Angola in the south. Periodic outbreaks of varying intensity occur, most frequently in West and East Africa ${ }^{70}$. It is estimated that $90 \%$ of YFV cases occur in Africa ${ }^{171}$. However, the burden of disease in Africa has proven difficult to measure due to the heterogeneity of clinical presentation of YFV. Modelling suggests $\sim 130,000$ severe cases of YFV occur each year, resulting in $\sim 78,000$ deaths ${ }^{170}$, mostly in West Africa. Only $12 \%$ of human 


\begin{tabular}{|c|c|c|c|c|c|c|}
\hline Virus & Antigenic group & $\begin{array}{l}\text { Primary } \\
\text { geographic } \\
\text { distribution }\end{array}$ & $\begin{array}{l}\text { Zoonotic } \\
\text { reservoir }\end{array}$ & $\begin{array}{l}\text { Transmission vector } \\
\text { and route }\end{array}$ & Human disease & $\begin{array}{l}\text { No. of human } \\
\text { infections }\end{array}$ \\
\hline Dengue & Dengue & $\begin{array}{l}\text { South America } \\
\text { Central America } \\
\text { North America } \\
\text { Asia } \\
\text { Australia } \\
\text { Africa }\end{array}$ & $\begin{array}{l}\text { Non-human } \\
\text { primates } \\
\text { (sylvatic cycle) }\end{array}$ & $\begin{array}{l}\text { A. aegypti } \\
\text { A. albopictus }\end{array}$ & $\begin{array}{l}\text { Dengue fever } \\
\text { Severe dengue } \\
\text { (vascular leakage, } \\
\text { shock) }\end{array}$ & $\begin{array}{l}390 \text { million } \\
\text { infections per } \\
\text { year }(\sim 30-50 \% \\
\text { are symptomatic) }\end{array}$ \\
\hline Zika & Spondweni & $\begin{array}{l}\text { Central America } \\
\text { South America } \\
\text { Africa } \\
\text { Asia } \\
\text { North America }\end{array}$ & $\begin{array}{l}\text { Non-human } \\
\text { primates } \\
\text { (sylvatic cycle) }\end{array}$ & $\begin{array}{l}\text { A. aegypti } \\
\text { A. albopictus } \\
\text { Sexual transmission } \\
\text { Vertical (mother to } \\
\text { fetus) }\end{array}$ & $\begin{array}{l}\text { Febrile syndrome } \\
\text { Guillian-Barré } \\
\text { syndrome } \\
\text { Congenital anomaly } \\
\text { Microcephaly }\end{array}$ & $\begin{array}{l}\text { Thousands } \\
\text { to millions } \\
\text { depending on the } \\
\text { year (since 2013) }\end{array}$ \\
\hline West Nile & Japanese encephalitis & $\begin{array}{l}\text { North America } \\
\text { Middle East } \\
\text { Africa } \\
\text { Europe } \\
\text { Australia }\end{array}$ & Birds & $\begin{array}{l}\text { C. pipiens } \\
\text { C. tarsalis }\end{array}$ & $\begin{array}{l}\text { Febrile syndrome } \\
\text { Meningitis } \\
\text { Encephalitis } \\
\text { Acute flaccid } \\
\text { paralysis }\end{array}$ & $\begin{array}{l}<10,000 \text { cases } \\
\text { per year }\end{array}$ \\
\hline Japanese encephalitis & Japanese encephalitis & $\begin{array}{l}\text { Asia } \\
\text { Australia }\end{array}$ & $\begin{array}{l}\text { Birds } \\
\text { Pigs }\end{array}$ & $\begin{array}{l}\text { Culex tritaeniorhynchus } \\
\text { Culex annulirostris }\end{array}$ & $\begin{array}{l}\text { Febrile syndrome } \\
\text { Meningitis } \\
\text { Encephalitis }\end{array}$ & $\begin{array}{l}70,000 \text { cases per } \\
\text { year }\end{array}$ \\
\hline Yellow fever & Yellow fever & $\begin{array}{l}\text { Africa } \\
\text { South America }\end{array}$ & $\begin{array}{l}\text { Non-human } \\
\text { primates } \\
\text { (sylvatic cycle) }\end{array}$ & A. aegypti & $\begin{array}{l}\text { Febrile syndrome } \\
\text { Liver failure } \\
\text { Haemorrhagic } \\
\text { syndrome }\end{array}$ & $\begin{array}{l}130,000 \text { severe } \\
\text { cases per year } \\
\text { ( }>50 \% \text { case } \\
\text { fatality rate) }\end{array}$ \\
\hline Powassan & Tick-borne flavivirus & $\begin{array}{l}\text { North America } \\
\text { Eastern Europe }\end{array}$ & $\begin{array}{l}\text { Rodents } \\
\text { Lagomorphs } \\
\text { Deer }\end{array}$ & $\begin{array}{l}\text { I. cookei } \\
\text { I. scapularis }\end{array}$ & $\begin{array}{l}\text { Febrile syndrome } \\
\text { Meningitis } \\
\text { Encephalitis }\end{array}$ & Hundreds \\
\hline Usutu & Japanese encephalitis & $\begin{array}{l}\text { Africa } \\
\text { Europe }\end{array}$ & Birds & C. pipiens & $\begin{array}{l}\text { Febrile syndrome } \\
\text { Meningitis } \\
\text { Encephalitis } \\
\text { Acute flaccid } \\
\text { paralysis }\end{array}$ & $\begin{array}{l}\text { Hundreds to } \\
\text { thousands }\end{array}$ \\
\hline Ilheus & Japanese encephalitis & $\begin{array}{l}\text { South America } \\
\text { Central America }\end{array}$ & $\begin{array}{l}\text { Birds } \\
\text { Non-human } \\
\text { primates(?) } \\
\text { Horses }\end{array}$ & $\begin{array}{l}\text { C. pipiens } \\
\text { Ochlerotatus serratus } \\
\text { Sabethes } \\
\text { Haemagogus }\end{array}$ & $\begin{array}{l}\text { Febrile syndrome } \\
\text { Encephalitis }\end{array}$ & Unknown \\
\hline Rocio & Japanese encephalitis & $\begin{array}{l}\text { South America } \\
\text { (Brazil only) }\end{array}$ & Birds(?) & $\begin{array}{l}\text { C. pipiens } \\
\text { C. tarsalis } \\
\text { Psorophora ferox }\end{array}$ & $\begin{array}{l}\text { Febrile syndrome } \\
\text { Encephalitis }\end{array}$ & Unknown \\
\hline Wesselsbron & Yellow fever & Africa & $\begin{array}{l}\text { Cattle } \\
\text { Sheep } \\
\text { Rats }\end{array}$ & $\begin{array}{l}\text { Aedes spp. } \\
\text { (Aedes caballus and } \\
\text { Aedes circumluteolus) }\end{array}$ & Febrile syndrome & Unknown \\
\hline Spondweni & Spondweni & $\begin{array}{l}\text { Africa } \\
\text { North America(?) }\end{array}$ & $\begin{array}{l}\text { Non-human } \\
\text { primates } \\
\text { (sylvatic cycle) }\end{array}$ & $\begin{array}{l}\text { Aedes, Culex, } \\
\text { Eretmapodites and } \\
\text { Mansonia }\end{array}$ & $\begin{array}{l}\text { Febrile syndrome } \\
\text { Vascular leakage } \\
\text { (shock) } \\
\text { Neurological } \\
\text { impairment }\end{array}$ & Unknown \\
\hline
\end{tabular}

This Table describes the primary geographic distribution, zoonotic reservoir, insect vector, clinical syndrome and estimated number of infections for a given flavivirus.

YFV infections in Africa are estimated to cause severe illness ${ }^{166}$. Prior to the late 1990s, the distribution of YFV in South America occurred predominantly in the river basins of the Orinoco, Amazon and Araguaia rivers. Since then, multiple outbreaks in humans and non-human primates (NHPs) have occurred outside this endemic region in Brazil, Columbia, Argentina, Ecuador and Peru ${ }^{172}$. This expanding activity is characterized by human infections proximal to major urban centres and large numbers of unvaccinated individuals.

The epidemiology of YFV is determined by the distribution of its mosquito vector. In South America, YFV is maintained in an enzootic cycle between canopy mosquitoes of the Haemogogus and
Sabethes genera and a variety of NHP species, whereas transmission among African primates is vectored by Aedes species mosquitoes ${ }^{169}$. These sylvatic cycles provide a reservoir for YFV and an opportunity for transmission when human activity encroaches on forest ecosystems. The presence of this reservoir virtually eliminates the possibility of YFV eradication through vaccination. Urban cycles of YFV transmission involving transmission cycles of $A$. aegypti and humans have not contributed significantly to YFV outbreaks in South America ${ }^{173}$. A study of the 2016-2017 YFV outbreak in Minas Gerais, Brazil, identified a temporal correlation between human infections and virus detection in NHPs, and established 


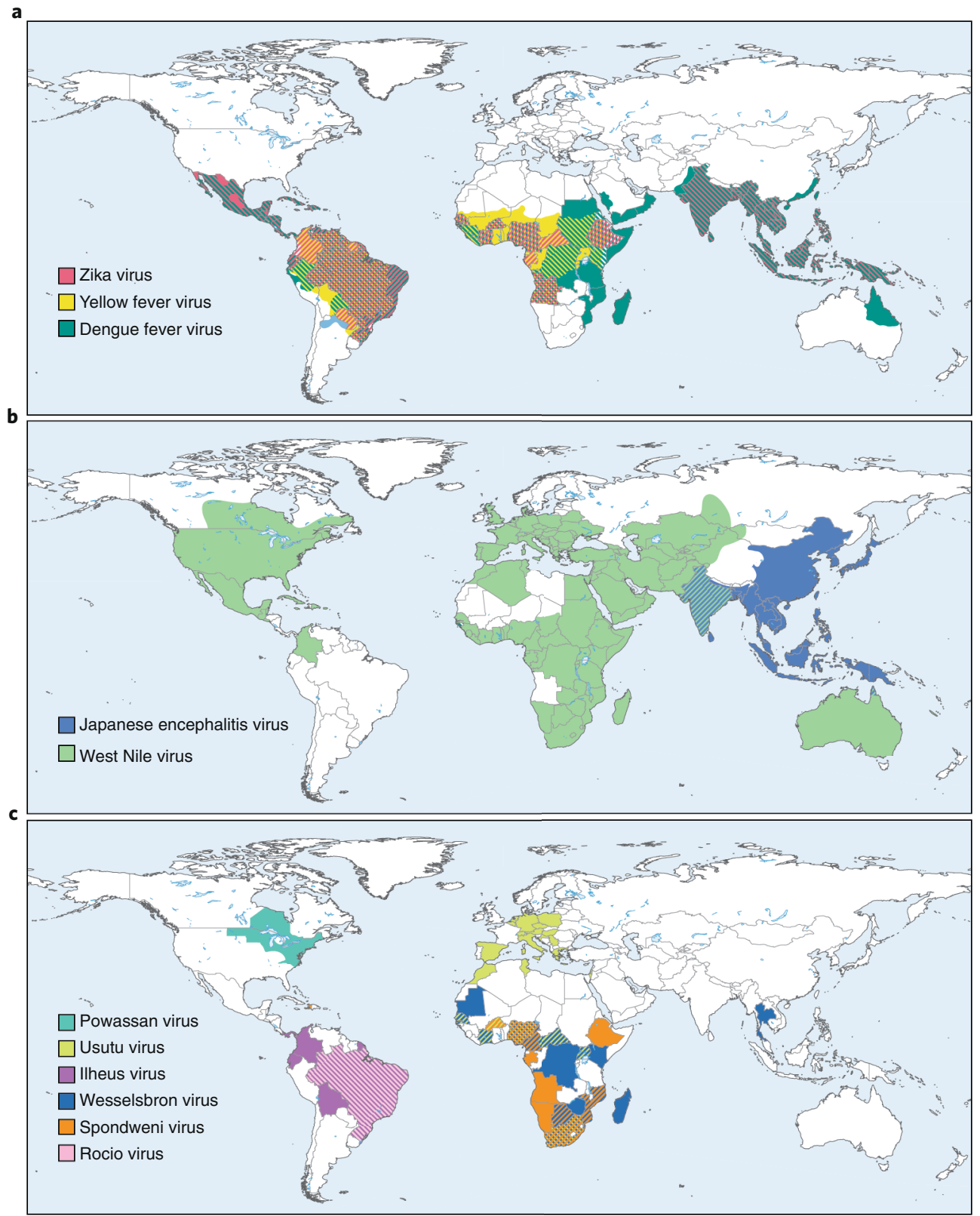

Fig. 4 | Global distribution of flaviviruses. a, The global distribution of Aedes-transmitted flaviviruses ZIKV, YFV and DENV are shown. b, The global distribution JEV and WNV is shown. c, The approximate geographic locations of flaviviruses with the potential for emergence in human populations. Image courtesy of Ethan Tyler.

that YFV-infected individuals lived an average of $1.4 \mathrm{~km}$ from a YFV-positive NHP sampled by this study (as compared to $39 \mathrm{~km}$ for non-exposed human controls $)^{5}$. The distribution of YFV cases in this outbreak also supported a model by which human infections originated from a sylvatic rather than urban cycle of enzootic transmission. While many factors contribute to the potential for YFV emergence in urban areas, the widespread distribution of A. aegypti populations capable of YFV transmission creates a significant risk for public health.

Zika virus. Prior to 2007, ZIKV was an obscure virus that caused a mild febrile illness in a small number of humans in Africa and parts of Asia. In late 2013 or early 2014, ZIKV was introduced into Brazil and other regions of the Americas ${ }^{174}$ with millions of infections occurring (Fig. 4). As part of this epidemic, some of the unique clinical features of ZIKV infection (for example, congenital malformations) were identified ${ }^{175,176}$ (Table 1). A key question is: how did ZIKV change to cause an epidemic of fetal microcephaly and other congenital anomalies?

Ecological factors have been proposed to explain the increased number of ZIKV infections in humans as a function of greater transmission by Aedes species mosquitoes. Potential factors that could have enhanced Aedes mosquito populations and transmission include changes in land use (for example, deforestation), climate change, population growth and human movement into urban areas ${ }^{177}$. Beyond this, changes in the ZIKV sequence during the pre- to post-epidemic transition may explain the expanded vector transmission. An alanine-to-valine (A188V) substitution in NS1 of epidemic ZIKV strains facilitated greater infectivity in A. aegypti laboratory mosquitoes and thus is postulated to enhance epidemic transmission ${ }^{178}$. 
Genetic changes in ZIKV also may have affected its ability to replicate and cause injury to key neuroprogenitor cells in the brain. Initial phylogenetic analysis revealed eleven amino acid changes between ancestral strains and French Polynesian and American ZIKV isolates, and these differences were dispersed in prM, NS1, NS3 and NS5 proteins ${ }^{179}$. Subsequent experiments showed that a serine-to-asparagine substitution (S139N of the polyprotein) in prM resulted in increased ZIKV infectivity in neuroprogenitor cells and more severe microcephaly in neonatal mice ${ }^{180}$. The S139N substitution arose just prior to the 2013 outbreak in French Polynesia and has been maintained in virtually all American strains. The basis for how the S139N mutation in prM mediates increased pathogenicity is uncertain, although it is speculated to affect the maturation state and/or physical structure of the ZIKV particle ${ }^{181}$.

Sequence changes in the 3'-UTR also may contribute to pathogenic effects in neural cells. One group identified a putative Musashi protein binding element in the stem-loop 2 (SL2) of the 3'-UTR, with changes immediately upstream of this site in epidemic strains ${ }^{182}$. As Musashi proteins regulate progenitor cell growth and differentiation through posttranscriptional control of gene expression, they speculated that the binding elements in the 3'-UTR of ZIKV would affect the fate of neuronal progenitor cells in infected cells and pathogenesis. A second group showed that Musashi-1 interacts with ZIKV RNA and facilitates viral replication ${ }^{183}$. ZIKV infection disrupted the binding of Musashi-1 to its endogenous targets, which altered expression of factors implicated in neural stem cell function and differentiation. Thus, Musashi protein interactions with RNA elements from epidemic strains of ZIKV may contribute to the vulnerability of the fetal brain to infection and development.

The same amino acid change in NS1 (A188V) in epidemic strains that is speculated to affect vector transmission also may affect replication in human cells. A188V variants of NS1 show enhanced binding to human TANK-binding kinase 1 (TBK1), an enzyme that regulates the activity and nuclear translocation of IRF3. NS1 binding to TBK1 resulted in reduced levels of TBK1 phosphorylation and diminished IFN- $\beta$ expression in human cells and mice ${ }^{184}$. Thus, this recent sequence change in NS1 can promote evasion of the innate immune response, enhance viraemia and possibly enhance ZIKV transmissibility from hosts to vectors, all of which facilitate epidemic transmission.

The immune status of the host may also influence ZIKV pathogenesis. While cross-reactive anti-DENV antibodies can readily enhance ZIKV infection in cell culture ${ }^{185,186}$, the significance of this finding to the epidemiology of ZIKV disease severity and transmission remains uncertain ${ }^{187}$. Indeed, passive transfer of cross-reactive, neutralizing E-dimer epitope antibodies raised against DENV prevented ZIKV pathogenesis in mice and NHPs ${ }^{188,189}$. However, in some settings, pre-existing anti-flavivirus antibodies have augmented ZIKV infection and disease; passive transfer of immune plasma raised against DENV or WNV enhanced ZIKV pathogenesis in Stat2 ${ }^{-/-}$mice ${ }^{190,191}$. Yet in another study in Ifnar $1^{-/-}$(A129) or Ifnar1 I $^{-/}$Ifngr $^{-/-}$(AG129) mice, whilst inactivated ZIKV vaccination enhanced dengue disease severity, ADE was not observed after ZIKV infection in animals that were passively immunized or pre-infected with DENV ${ }^{181}$. Apart from the contrasting results, a major caveat to the passive transfer of antibody model is that these mice lack immune, cross-reactive $\mathrm{CD} 8^{+} \mathrm{T}$ cells, which can limit the pathological effects of ADE in the context of DENV immunity and subsequent ZIKV infection, including during pregnancy ${ }^{127,192}$.

In NHPs, the effects of pre-existing flavivirus immunity on ZIKV and DENV pathogenesis are also uncertain. In one study, no substantive differences in ZIKV infection viral titers, neutralizing antibody levels or immune cell kinetics were observed after inoculation of naïve and flavivirus-immune rhesus macaques ${ }^{193}$. Other groups also have found no evidence of enhancement of ZIKV pathogenesis in DENV-immune macaques ${ }^{194,195}$. However, in a study in rhesus macaques, prior exposure to ZIKV resulted in enhanced DENV peak viraemia ${ }^{196}$, and this was associated with delayed induction of memory cross-neutralizing antibody responses ${ }^{197}$. This observation may have implications for ZIKV vaccine development in areas endemic for DENV infections. More epidemiological studies in humans are necessary to establish whether clinically relevant ADE of ZIKV pathogenesis occurs. An analysis of Brazilian cohorts has not shown evidence of $\mathrm{ADE}$, greater disease severity or effects on birth outcomes in DENV-experienced patients with acute ZIKV infection ${ }^{198,199}$.

\section{The next possible emerging flaviviruses}

The ZIKV epidemic showed that flaviviruses of relative obscurity can emerge as significant public health threats within a compressed time frame. Are there other esoteric flaviviruses that will appear soon and cause epidemics in vulnerable hosts? While it is difficult to predict the rise of a particular pathogen in the human population, six less well known flaviviruses could emerge to cause significant human disease in the near future (Fig. 4; Table 1).

Spondweni virus. Spondweni virus (SPOV) is the flavivirus most closely related to ZIKV. In the 1950s, SPOV was isolated from patients in Nigeria and South Africa ${ }^{200,201}$, and subsequently circulated in sub-Saharan Africa. Although most symptomatic SPOV infections result in mild illness, a subset reportedly progresses to more serious disease, including vascular leakage and shock or neurological involvement ${ }^{202}$. The enzootic cycle of SPOV likely is between mosquitoes and NHPs ${ }^{203}$. Historically, SPOV infection was not observed in A. aegypti, Aedes albopictus and Culex quinquefasciatus mosquitoes, and instead was isolated from other mosquitoes in the genera Aedes, Culex, Eretmapodites and Mansonia. Based on this vector biology, the potential for urban epidemic cycles of SPOV was considered low. However, the epidemiology may be changing, as SPOV was reportedly detected in field-caught C. quinquefasciatus mosquitoes in Haiti in 2016 (ref. ${ }^{204}$ ). This finding suggests that SPOV may adapt to mosquito species that preferentially feed on humans. Given its relationship to ZIKV ( $75 \%$ amino acid identity), there is concern that SPOV also might have the capacity to infect cells of the reproductive tract and be sexually transmitted in humans, as was reported in mice ${ }^{205}$.

Usutu virus. USUV is a mosquito-transmitted flavivirus belonging to the JEV antigenic complex. USUV is classified into eight lineages with two major African and European groups ${ }^{206}$. USUV shares the same mosquito vectors (for example, Culex pipiens) with WNV and similar bird populations as amplifying hosts, and the two viruses can co-circulate ${ }^{207}$. Initially isolated in 1959 in South Africa, USUV appeared in 1996 in Italy (based on retrospective analysis of archived tissues) and in Central Europe in 2001, where it was associated with deaths in selected avian populations ${ }^{208}$. In 20152016, widespread USUV activity was reported in Germany, France, Austria, Belgium and the Netherlands, with mortality observed in blackbirds and grey owls ${ }^{209}$. USUV infection occurs in humans and seroprevalence studies suggest that it may be higher than WNV in areas of co-circulation ${ }^{210}$. Neuroinvasive disease in humans caused by USUV appears less common than WNV, although reports of meningoencephalitis, meningitis and paralysis exist ${ }^{211}$. As WNV and USUV are related ( $76 \%$ amino acid identity), serological distinction may be challenging and thus, it is possible that USUV infection and disease are underestimated.

Ilheus virus. Ilheus virus (ILHV) is a mosquito-transmitted flavivirus closely related to viruses of the JEV serocomplex. It was first described in Brazil in 1944 and now circulates in South America where it sporadically causes a febrile syndrome in humans that can progress to encephalitis. ILHV infection in humans has been reported in Trinidad, Panama, Colombia, French Guyana, Brazil, 
Ecuador and Bolivia ${ }^{212}$. ILHV cycles in nature between birds and mosquitoes, and has been isolated from mosquitoes, sentinel monkeys, humans ${ }^{213}$ and birds. Moreover, high seroprevalence rates of ILHV have been detected in horses in parts of Brazil ${ }^{214}$. As this virus can propagate in some mosquitoes that feed on humans (such as the Aedes and Culex species) ${ }^{215}$, there is the potential for more extensive zoonotic emergence in the human population.

Rocio virus. Rocio virus (ROCV) is a flavivirus in the JEV serocomplex and is closely related to ILHV. It was first isolated in 1975 from the brain of an affected individual during an epidemic of encephalitis in São Paulo, Brazil ${ }^{216}$. Its spread to more than 20 municipalities resulted in approximately 1,000 diagnosed cases ${ }^{217}$. During the epidemic, there was a case-fatality rate of $13 \%$, with approximately $20 \%$ of survivors developing long-term neurological sequelae. Laboratory studies suggest that ROCV is mosquito-transmitted, as Culex tarsalis and C. pipiens were efficient experimental vectors ${ }^{218}$, and that birds may act as amplifying hosts ${ }^{219}$. Although no cases of ROCV infection and encephalitis have been reported after the initial outbreak, serological surveys suggest ROCV transmission among humans and animals in different regions of Brazil is still actively occurring ${ }^{220,221}$.

Wesselsbron virus. Wesselsbron virus (WSLV) is a mosquitotransmitted zoonotic agent that causes disease in sheep and other ruminants in Africa with spillover into human populations. WSLV infection was initially reported on a sheep farm in South Africa in 1955 and caused substantial mortality in newborn lambs and abortion in pregnant ewes ${ }^{213}$. In humans, WSLV infection can cause a sudden onset of influenza-like illness characterized by fever, rigors, headache, myalgia and arthralgia. Historical studies have suggested that WSLV circulation is widespread-at least in southern Africa $^{213}$-and more recent analysis has demonstrated infection of rats, which could serve as a reservoir ${ }^{222}$. WSLV is likely present in many areas of Africa as viral isolations from mosquitoes have been reported in South Africa, Botswana, Zimbabwe, Uganda, Mozambique, Cameroon, Central African Republic, Mauritania, Senegal, Nigeria, Democratic Republic of Congo and Madagascar ${ }^{213}$. There is concern that WSLV could emerge beyond its traditional borders, spread more extensively and cause infection and disease in naïve human populations. Indeed, WSLV was isolated in Thailand from mosquitoes in 1966, although there is no recent evidence of circulation or transmission in Asia.

Tick-borne flaviviruses. Transmission of tick-borne flaviviruses has been increasing worldwide. This group includes TBEV, which is principally located in regions of northern China and Japan, Russia, and Central and Eastern Europe, and can cause fatal neurological syndromes. TBEV causes several thousands of human cases per year, with recent increases attributed to changes in climate, population dynamics, the range of permissive ticks and shifts in land usage ${ }^{223,224}$. Other antigenically related tick-borne flaviviruses can cause severe human disease. This group includes Omsk haemorrhagic fever virus (OHFV), POWV, Kyasanur forest disease virus (KFDV), Alkhurma haemorrhagic fever virus (AHFV) and Karshi virus (KSIV), with some causing encephalitis (KSIV and POWV) and others resulting in haemorrhagic fever (OHFV, KFDV and AHFV).

POWV is the only known tick-borne flavivirus that circulates in North America. POWV was first isolated from a child who died of encephalitis in Powassan, Ontario in 1958. Human cases of POWV occur in the United States, Canada and also Russia ${ }^{225}$. Two genetic lineages of POWV circulate in North America, lineage I and lineage II (also called deer-tick virus (DTV)) that share at least $96 \%$ amino acid identity in their E proteins. POWV lineage I strains are predominantly maintained in Ixodes cookei ticks, whereas lineage II strains are found in Ixodes scapularis deer ticks ${ }^{226}$.
The natural cycle of POWV includes small mammals (such as rodents and lagomorphs), deer and ticks ${ }^{227}$, with peak transmission occurring during spring and summer. In humans, POWV infections can cause severe neuroinvasive disease, including meningitis and encephalitis, with an estimated case-fatality rate of $10-30 \%$ and with many survivors suffering long-term disabling sequelae. While POWV-induced disease can occur in all age groups, epidemiological studies suggest a greater risk in the elderly $(>60 \text { years of age })^{224}$, which is similar to other encephalitic flaviviruses including $\mathrm{WNV}^{228}$. POWV is emerging, as increasing numbers of cases have been diagnosed over the past decade ${ }^{229}$ and up to $3-5 \%$ of I. scapularis ticks isolated in certain parts of the United States now test positive for POWV $^{230,231}$. Moreover, seroprevalence rates of POWV infection in other mammals (for example, white-tailed deer) are rising and may be associated with the expanded range of I. scapularis in the United States $^{232}$. Thus, an abundance of evidence suggests that POWV is an emerging flavivirus threat, which has triggered the development of countermeasures to minimize severe disease ${ }^{233}$.

\section{Combating flavivirus emergence}

Given the ongoing and likely future threats of flavivirus infections, the continued development and deployment of countermeasures that limit epidemic spread and disease in humans is urgent. This section focuses on the past successes and future challenges of flavivirus vaccines and the issues related to the development of direct-acting antiviral agents.

Flavivirus vaccines. Licensed vaccines exist for five flaviviruses (YFV, DENV, JEV, KFDV and TBEV), and several others have been evaluated in preclinical and clinical studies. The live-attenuated YFV vaccine is among the most successful of all vaccines to prevent viral infections. Developed by Max Theiler in 1939 by iterative passage of the pathogenic Asibi strain in mouse and chicken embryos, more than 500 million doses of YFV 17D vaccine have been administered worldwide ${ }^{234}$. SA14-14-2, an extensively passaged vaccine for JEV, is also efficacious and is used extensively in Asia and India ${ }^{235}$. Molecular clone technology enabled the development of rationally-attenuated vaccines for DENV ${ }^{236-240}$ and JEV ${ }^{241}$ via the construction of chimeric viruses or those encoding deletions in the 3'-UTR of the genome. Additional modes of attenuation (for example, mutations in E, NS1 or NS5 genes) have been evaluated as flavivirus vaccine candidates in preclinical models ${ }^{242,243}$. Chemically-inactivated viruses of cell culture-derived viruses are currently used as vaccines for $\mathrm{JEV}^{244}, \mathrm{TBEV}^{245}$ and $\mathrm{KFDV}^{246}$. While they are protective, they require frequent iterative boosting to maintain protective immunity.

The severe clinical outcomes following DENV infections have made the development of a vaccine a global health imperative. However, vaccine design and development has been hampered by the risk that incomplete vaccine immunity against all four serotypes might paradoxically enhance pathogenesis in the setting of subsequent natural infection. As a result, the goal is to develop a vaccine that simultaneously elicits a balanced tetravalent neutralizing response against all four DENV serotypes. The live-attenuated, tetravalent Dengvaxia (from Sanofi Pasteur) was the first anti-DENV vaccine licensed in 2016, although it was restricted to individuals greater than 9 years of age ${ }^{247}$. In 2019, the United States Food and Drug Administration (FDA) approved Dengvaxia, but only for use in individuals between 9-16 years of age who have laboratory-confirmed prior dengue infection and are living in endemic areas. These relatively narrow indications are based in part on the finding that in the clinical trials, vaccinated children aged between 2-5 years were at greater risk of hospitalization as compared to controls ${ }^{248}$. Serological studies later demonstrated that individuals that were DENV-seropositive at the time of vaccine administration experienced benefit from Dengvaxia ${ }^{249}$, whereas DENV-naïve 
individuals were at increased risk for disease over this interval ${ }^{250}$. Further follow-up is required to evaluate the public health impact of the use of this vaccine candidate on children since its licensure. As two other live-attenuated tetravalent DENV vaccines (TV003 from the National Institute of Allergy and Infectious Diseases, and TAK003 from Takeda Pharmaceutical Company) are in advanced stages of clinical trials ${ }^{251,252}$, the question remains as to whether they will provide superior protection to naïve individuals without the risk of sensitizing them to symptomatic or severe disease from subsequent natural DENV infection.

Despite the success of vaccines for some flaviviruses, challenges exist for the development of vaccine candidates to blunt epidemics caused by emerging flaviviruses. First, the extensive cross-reactivity of flavivirus-immune sera complicates the development and use of diagnostics to track and manage outbreaks. While neutralization assays provide some capacity to resolve antibody responses to homologous and heterologous viruses in convalescent sera, these approaches have limitations in sera from acutely infected individuals ${ }^{253,254}$. Since viraemia is typically transient, molecular assays to detect flavivirus infection are sensitive only for relatively small intervals after exposure, the timing of which is often unknown. While the discovery that RNA persists in the urine and semen of ZIKV-infected individuals extended the utility of these approaches during the 2015 epidemic $^{72}$, serological assays remain an important tool for the management of the epidemics and evaluation of vaccine candidates ${ }^{255,256}$. Second, the presence of cross-reactive antibodies may shape the immune response to vaccination and influence the outcome of disease following infection, as reviewed elsewhere ${ }^{110}$. Third, while promising new platforms have been applied to create flavivirus vaccines, including synthetic nucleic expression systems, small differences in antigen design unpredictably modulate the potency of the immune response to vaccination, highlighting the need for additional study of the biology, structure and heterogeneity of vaccine antigens ${ }^{257}$. Fourth, even large epidemics of flavivirus infection and disease can be transient relative to the interval required to the development and evaluation of vaccine candidates. Despite the unprecedented speed of generating Zika virus vaccine candidates for early clinical evaluation, a requirement for advanced clinical trials in larger numbers of individuals to reveal efficacy and provide insights into correlates of protection may be jeopardized by the smaller number of new infections, which is characteristic of a waning epidemic ${ }^{258}$. Finally, limited availability or insufficient deployment may limit the utility of vaccines once developed. Notably, vaccine shortages have exacerbated ongoing YFV activity in South America and Africa, prompting vaccine sparing studies ${ }^{259}$. Moreover, considerable numbers of JEV and TBEV infections continue to occur in Asia and Europe despite the availability of safe and effective vaccine programs. Even when made available, effective vaccines have not always had the desired impact on global health.

Anti-flavivirus drugs. The development of antiviral therapeutics will enable new approaches for the management of flavivirus outbreaks due to their potential for use as treatment and prophylaxis. Flaviviruses encode multiple potential targets for small molecule drugs. Extensive drug-discovery efforts have focused on the NS5 and NS3 proteins encoding enzymatic activity required for viral genome replication and polyprotein processing. Nucleoside ${ }^{260}$ and allosteric inhibitors ${ }^{261}$ of NS5-encoded RNA-dependent RNA polymerase activity have been described (reviewed in ref. ${ }^{262}$ ). Compounds with broad activity against multiple classes of viruses, including flaviviruses, have also been characterized, including the adenosine analogue BCX4430 (refs. ${ }^{263,264}$ ) and the nucleotide analogue prodrug Sofosbuvir ${ }^{265}$. The methyltransferase domain that comprises the amino terminus of NS5 responsible for the N-7 and 2'-O methylation of the viral RNA cap also is a potential target for small molecules ${ }^{266,267}$. Inhibition of viral protease activity has yielded important classes of drugs for multiple viruses, including hepatitis $C$, and has been aggressively pursued for other flaviviruses. While inhibitor design was guided by numerous structures of the NS3 protease in complex with NS2B, this complex has proven to be a challenging target due to the relatively flat structure of the substrate pocket, that ligands binding this motif are charged, and the conformational flexibility of the protease target ${ }^{268,269}$. Both small molecule and peptide protease inhibitors have been characterized; some of these function via an allosteric mechanism. Of interest, multiple repurposed compounds have been shown to inhibit flavivirus proteases, including several FDA-approved drugs capable of inhibiting ZIKV replication in cell culture and mice ${ }^{270,271}$. Flavivirus helicase inhibitors also have been characterized in preclinical studies ${ }^{272}$.

Structural proteins of the virion also may be targeted by antiviral compounds. Crystallographic studies of the E protein of DENV2 identified a lipid molecule in a hydrophobic pocket formed at the junction between ED-II and E-DI ${ }^{273}$. Compounds that target this pocket have been identified and are thought to block infection by interfering with the viral membrane fusion process ${ }^{274,275}$. Peptides derived from sequences present in the stem anchor domains of $\mathrm{E}$ also have antiviral activity ${ }^{276,277}$. The internal capsid protein has also been targeted for drug discovery efforts. High-throughput screening identified the small molecule ST-148 as capable of inhibiting cell death in a DENV propagation assay ${ }^{278}$. The proposed mechanism of this molecule is the stabilization of the capsid protein, which results in altered assembly and disassembly during virus entry ${ }^{279}$. A second chemically related compound has been described that also binds DENV capsid and inhibits infection ${ }^{280}$.

Targeting the vector. Progress has been made in reducing flavivirus transmission by limiting infection of the mosquito host ${ }^{281}$. For example, the infection of $A$. aegypti mosquitoes with selected strains of endosymbiotic Wolbachia resulted in bacterial invasion of mosquito populations and interference with DENV and ZIKV replication $^{282,283}$. The $w \mathrm{Mel}$ strain of Wolbachia-infected A. aegypti, when directly fed on viraemic dengue patients, has lower DENV transmission potential than their wild-type counterparts ${ }^{284}$. Mechanistic studies suggest that infection with Wolbachia reduces flavivirus replication, is associated with rapid viral RNA degradation in the cytoplasm and is mediated by the mosquito XRN1 enzyme ${ }^{285}$. The establishment of $A$. aegypti strains with Wolbachia infection in an endemic setting could abolish or reduce flavivirus transmission $^{286}$. Wolbachia-infected A. aegypti mosquitoes have been released in Australia where outbreaks of dengue fever occur, and have been stable over several years ${ }^{287}$. The AWED trial (Applying Wolbachia to Eliminate Dengue) is underway to assess the efficacy of Wolbachia-infected mosquito deployments to reduce DENV incidence in Indonesia ${ }^{288}$.

Other groups have created genetically engineered $A$. aegypti mosquitoes that are resistant to DENV infection through the induction of an antiviral RNA interference response ${ }^{289}$. More recently, a polycistronic cluster of engineered, synthetic small RNAs targeting ZIKV was expressed in the midgut of mosquitoes, a site of early virus infection. Engineered $A$. aegypti mosquitoes harbouring the anti-ZIKV transgene had markedly reduced viral infection, dissemination and transmission rates of ZIKV in the laboratory ${ }^{290}$.

\section{Conclusions}

The recent outbreaks of less well-known flaviviruses highlight the transmission potential and dynamic state of emergence. While it is challenging to predict which flavivirus will transition next from relative obscurity to worldwide notoriety, their changing epidemiology raises concern for large-scale emergence and disease. Sustained research efforts on flaviviruses and likely other arboviruses (for example, alphaviruses, bunyaviruses and some orthomyxoviruses) are needed. Such a concerted program can prepare us to respond 
rapidly with countermeasures to new viral epidemics that cause known and unanticipated clinical syndromes.

A requirement to respond rapidly to an explosive ZIKV outbreak in the Americas identified aspects of flavivirus biology that may be particularly important for future preparedness efforts. While expensive to establish and maintain, surveillance programs to identify the changes in pathogen distribution that provide early signals to public health officials are critical, as has become clear with the global pandemic of severe acute respiratory syndrome coronavirus 2 infecton and COVID-19 disease. The emergence of WNV in North America in 1999 resulted in a considerable increase in arbovirus surveillance capacity to manage this outbreak, but this was not sustained ${ }^{291}$. The development of sensitive and specific flavivirus diagnostics is a challenge due to serological cross-reactivity and the relatively limited persistence of viral RNA in those infected. These technical obstacles hamper the management of an outbreak response, including the evaluation of vaccines. Enhanced and sustained investment in these areas are critical for an effective response to future flavivirus threats. Antibody discovery efforts for emerging flaviviruses will be a powerful component of preparedness efforts because they inform the development of diagnostics, allow for characterization of vaccine antigens and identify protective features of the immune response. Moreover, in vivo expression of potent flavivirus-reactive neutralizing antibodies using recently developed synthetic gene-expressing platforms, such as modified messenger RNA, provides a rapid pathway for the development of therapeu$\operatorname{tics}^{292}$. While these gene-expression platforms also enable the rapid development of vaccine candidates, an understanding of structureimmunogen relationships and the correlates of protection may be insufficient to ensure rapid success for understudied flaviviruses in an outbreak setting. A continued emphasis on obtaining a fundamental understanding of the structure(s) of flavivirus vaccine antigens, the genetic and functional components of the antibody response to infection and vaccination, and viral pathogenesis in animal models strengthens our capacity to respond quickly to the next flavivirus threat. Because flaviviruses share an overall similar structure, antigen designs that lack features recognized by cross-reactive antibodies and that are compatible with increasingly powerful antigen expression or display platforms, may be particularly important first-generation vaccine candidates for use in an increasingly flavivirus-experienced world.

Received: 27 September 2019; Accepted: 27 March 2020; Published online: 4 May 2020

\section{References}

1. Bhatt, S. et al. The global distribution and burden of dengue. Nature 496, 504-507 (2013).

2. Gubler, D. J. Dengue/dengue haemorrhagic fever: history and current status. Novartis Found. Symp. 277, 3-16 (2006)

3. Pierson, T. C. \& Diamond, M. S. The emergence of Zika virus and its new clinical syndromes. Nature 560, 573-581 (2018).

4. Roehrig, J. T. West Nile virus in the United States - a historical perspective. Viruses 5, 3088-3108 (2013).

5. Faria, N. R. et al. Genomic and epidemiological monitoring of yellow fever virus transmission potential. Science 361, 894-899 (2018).

6. Ingelbeen, B. et al. Urban yellow fever outbreak-Democratic Republic of the Congo, 2016: towards more rapid case detection. PLoS Negl. Trop. Dis. 12, e0007029 (2018).

7. Ling, Y. et al. Yellow fever in a worker returning to China from Angola, March 2016. Emerg. Infect. Dis. 22, 1317-1318 (2016).

8. Young, P. R. Arboviruses: a family on the move. Adv. Exp. Med. Biol. 1062, $1-10$ (2018).

9. Tabachnick, W. J. Climate change and the arboviruses: lessons from the evolution of the dengue and yellow fever viruses. Annu. Rev. Virol. 3, 125-145 (2016).

10. Mansfield, K. L., Hernandez-Triana, L. M., Banyard, A. C., Fooks, A. R. \& Johnson, N. Japanese encephalitis virus infection, diagnosis and control in domestic animals. Vet. Microbiol. 201, 85-92 (2017).
11. Jeffries, C. L. et al. Louping ill virus: an endemic tick-borne disease of Great Britain. J. Gen. Virol. 95, 1005-1014 (2014).

12. McLean, R. G., Ubico, S. R., Bourne, D. \& Komar, N. West Nile virus in livestock and wildlife. Curr. Top. Microbiol. Immunol. 267, 271-308 (2002).

13. Venter, M. Assessing the zoonotic potential of arboviruses of African origin. Curr. Opin. Virol. 28, 74-84 (2018).

14. Zhang, W., Chen, S., Mahalingam, S., Wang, M. \& Cheng, A. An updated review of avian-origin Tembusu virus: a newly emerging avian Flavivirus. J. Gen. Virol. 98, 2413-2420 (2017).

15. Pandit, P. S. et al. Predicting wildlife reservoirs and global vulnerability to zoonotic Flaviviruses. Nat. Commun. 9, 5425 (2018).

16. Sirohi, D. \& Kuhn, R. J. Zika virus structure, maturation, and receptors J. Infect. Dis. 216, S935-S944 (2017).

17. Akey, D. L. et al. Flavivirus NS1 structures reveal surfaces for associations with membranes and the immune system. Science 343, 881-885 (2014).

18. Murthy, H. M., Clum, S. \& Padmanabhan, R. Dengue virus NS3 serine protease. Crystal structure and insights into interaction of the active site with substrates by molecular modeling and structural analysis of mutational effects. J. Biol. Chem. 274, 5573-5580 (1999); retraction 284, 34468 (2009).

19. Wu, J., Bera, A. K., Kuhn, R. J. \& Smith, J. L. Structure of the Flavivirus helicase: implications for catalytic activity, protein interactions, and proteolytic processing. J. Virol. 79, 10268-10277 (2005).

20. Shi, Y. \& Gao, G. F. Structural biology of the Zika virus. Trends Biochem. Sci. 42, 443-456 (2017).

21. Rey, F. A., Heinz, F. X., Mandl, C., Kunz, C. \& Harrison, S. C. The envelope glycoprotein from tick-borne encephalitis virus at $2 \AA$ resolution. Nature 375, 291-298 (1995)

22. Rey, F. A., Stiasny, K. \& Heinz, F. X. Flavivirus structural heterogeneity: implications for cell entry. Curr. Opin. Virol. 24, 132-139 (2017).

23. Lorenz, I. C., Allison, S. L., Heinz, F. X. \& Helenius, A. Folding and dimerization of tick-borne encephalitis virus envelope proteins prM and $\mathrm{E}$ in the endoplasmic reticulum. J. Virol. 76, 5480-5491 (2002).

24. Prasad, V. M. et al. Structure of the immature Zika virus at $9 \AA$ resolution. Nat. Struct. Mol. Biol. 24, 184-186 (2017).

25. Elshuber, S., Allison, S. L., Heinz, F. X. \& Mandl, C. W. Cleavage of protein prM is necessary for infection of BHK-21 cells by tick-borne encephalitis virus. J. Gen. Virol. 84, 183-191 (2003).

26. Kostyuchenko, V. A. et al. Structure of the thermally stable Zika virus. Nature 533, 425-428 (2016).

27. Sirohi, D. et al. The $3.8 \AA$ resolution cryo-EM structure of Zika virus. Science 352, 467-470 (2016).

28. Mukhopadhyay, S., Kim, B. S., Chipman, P. R., Rossmann, M. G. \& Kuhn, R. J. Structure of West Nile virus. Science 302, 248 (2003).

29. Kuhn, R. J. et al. Structure of dengue virus: implications for flavivirus organization, maturation, and fusion. Cell 108, 717-725 (2002).

30. Byk, L. A. \& Gamarnik, A. V. Properties and functions of the dengue virus capsid protein. Annu. Rev. Virol. 3, 263-281 (2016)

31. Therkelsen, M. D. et al. Flaviviruses have imperfect icosahedral symmetry. Proc. Natl Acad. Sci. USA 115, 11608-11612 (2018).

32. Amberg, S. M. \& Rice, C. M. Mutagenesis of the NS2B-NS3-mediated cleavage site in the flavivirus capsid protein demonstrates a requirement for coordinated processing. J. Virol. 73, 8083-8094 (1999).

33. Tassaneetrithep, B. et al. DC-SIGN (CD209) mediates dengue virus infection of human dendritic cells. J. Exp. Med. 197, 823-829 (2003).

34. Navarro-Sanchez, E. et al. Dendritic-cell-specific ICAM3-grabbing non-integrin is essential for the productive infection of human dendritic cells by mosquito-cell-derived dengue viruses. EMBO Rep. 4, 723-728 (2003).

35. Chen, Y. et al. Dengue virus infectivity depends on envelope protein binding to target cell heparan sulfate. Nat. Med. 3, 866-871 (1997).

36. Meertens, L. et al. The TIM and TAM families of phosphatidylserine receptors mediate dengue virus entry. Cell Host Microbe 12, 544-557 (2012).

37. Corver, J. et al. Membrane fusion activity of tick-borne encephalitis virus and recombinant subviral particles in a liposomal model system. Virology 269, 37-46 (2000).

38. Gollins, S. W. \& Porterfield, J. S. pH-dependent fusion between the flavivirus West Nile and liposomal model membranes. J. Gen. Virol. 67, 157-166 (1986).

39. Miner, J. J. et al. The TAM receptor Mertk protects against neuroinvasive viral infection by maintaining blood-brain barrier integrity. Nat. Med. 21 1464-1472 (2015)

40. Chen, J. et al. AXL promotes Zika virus infection in astrocytes by antagonizing type I interferon signalling. Nat. Microbiol. 3, 302-309 (2018).

41. Wang, $\mathrm{S}$. et al. Integrin $\alpha \mathrm{v} \beta 5$ internalizes Zika virus during neural stem cells infection and provides a promising target for antiviral therapy. Cell Rep. 30, 969-983 (2020).

42. Zhu, Z. et al. Zika virus targets glioblastoma stem cells through a SOX2-integrin $\alpha v \beta 5$ axis. Cell Stem Cell. 26, 187-204 (2020). 
43. Hackett, B. A. \& Cherry, S. Flavivirus internalization is regulated by a size-dependent endocytic pathway. Proc. Natl Acad. Sci. USA 115, 4246-4251 (2018).

44. Hackett, B. A. et al. RNASEK is required for internalization of diverse acid-dependent viruses. Proc. Natl Acad. Sci. USA 112, 7797-7802 (2015).

45. Perreira, J. M. et al. RNASEK is a V-ATPase-associated factor required for endocytosis and the replication of rhinovirus, influenza A virus, and dengue virus. Cell Rep 12, 850-863 (2015).

46. Chao, L. H., Klein, D. E., Schmidt, A. G., Pena, J. M. \& Harrison, S. C. Sequential conformational rearrangements in flavivirus membrane fusion. eLife 3, e04389 (2014).

47. Chao, L. H. et al. How small-molecule inhibitors of dengue-virus infection interfere with viral membrane fusion. eLife 7, e36461 (2018).

48. Gebhard, L. G., Filomatori, C. V. \& Gamarnik, A. V. Functional RNA elements in the dengue virus genome. Viruses 3, 1739-1756 (2011).

49. Barrows, N. J. et al. Biochemistry and molecular biology of flaviviruses. Chem. Rev. 118, 4448-4482 (2018).

50. Aktepe, T. E. \& Mackenzie, J. M. Shaping the flavivirus replication complex: It is curvaceous! Cell. Microbiol. 20, e12884 (2018).

51. Welsch, S. et al. Composition and three-dimensional architecture of the dengue virus replication and assembly sites. Cell Host Microbe 5 , 365-375 (2009).

52. Jordan, T. X. \& Randall, G. Flavivirus modulation of cellular metabolism. Curr. Opin. Virol. 19, 7-10 (2016).

53. Heaton, N. S. \& Randall, G. Dengue virus and autophagy. Viruses 3, 1332-1341 (2011).

54. Aktepe, T. E., Liebscher, S., Prier, J. E., Simmons, C. P. \& Mackenzie, J. M. The host protein reticulon $3.1 \mathrm{~A}$ is utilized by flaviviruses to facilitate membrane remodelling. Cell Rep. 21, 1639-1654 (2017).

55. Yi, Z., Yuan, Z., Rice, C. M. \& MacDonald, M. R. Flavivirus replication complex assembly revealed by DNAJC14 functional mapping. J. Virol. 86, 11815-11832 (2012)

56. Acosta, E. G. \& Bartenschlager, R. The quest for host targets to combat dengue virus infections. Curr. Opin. Virol. 20, 47-54 (2016).

57. Burger-Calderon, R. et al. Zika virus infection in Nicaraguan households. PLoS Negl. Trop. Dis. 12, e0006518 (2018).

58. Endy, T. P. et al. Epidemiology of inapparent and symptomatic acute dengue virus infection: a prospective study of primary school children in Kamphaeng Phet, Thailand. Am. J. Epidemiol. 156, 40-51 (2002).

59. Mostashari, F. et al. Epidemic West Nile encephalitis, New York, 1999: results of a household-based seroepidemiological survey. Lancet 358, 261-264 (2001).

60. Lim, J. K. et al. Genetic deficiency of chemokine receptor CCR5 is a strong risk factor for symptomatic West Nile virus infection: a meta-analysis of 4 cohorts in the US epidemic. J. Infect. Dis. 197, 262-265 (2008).

61. Sakuntabhai, A. et al. A variant in the CD209 promoter is associated with severity of dengue disease. Nat. Genet. 37, 507-513 (2005).

62. Murray, K. et al. Risk factors for encephalitis and death from West Nile virus infection. Epidemiol. Infect. 134, 1325-1332 (2006).

63. Iwamoto, M. et al. Transmission of West Nile virus from an organ donor to four transplant recipients. N. Engl. J. Med. 348, 2196-2203 (2003).

64. Thackray, L. B. et al. Oral antibiotic treatment of mice exacerbates the disease severity of multiple flavivirus infections. Cell Rep. 22, 3440-3453 (2018).

65. Ngo, N. T. et al. Acute management of dengue shock syndrome: a randomized double-blind comparison of 4 intravenous fluid regimens in the first hour. Clin. Infect. Dis. 32, 204-213 (2001).

66. Rothman, A. L. Immunity to dengue virus: a tale of original antigenic sin and tropical cytokine storms. Nat. Rev. Immunol. 11, 532-543 (2011).

67. Beatty, P. R. et al. Dengue virus NS1 triggers endothelial permeability and vascular leak that is prevented by NS1 vaccination. Sci. Transl. Med. 7, 304ra141 (2015).

68. Puerta-Guardo, H., Glasner, D. R. \& Harris, E. Dengue virus NS1 disrupts the endothelial glycocalyx, leading to hyperpermeability. PLoS Pathog. 12, e1005738 (2016).

69. Vieira, W. T., Gayotto, L. C., de Lima, C. P. \& de Brito, T. Histopathology of the human liver in yellow fever with special emphasis on the diagnostic role of the Councilman body. Histopathology 7, 195-208 (1983).

70. Monath, T. P. \& Vasconcelos, P. F. Yellow fever. J. Clin. Virol. 64, 160-173 (2015)

71. Miner, J. J. \& Diamond, M. S. Zika virus pathogenesis and tissue tropism. Cell Host Microbe 21, 134-142 (2017).

72. Mansuy, J. M. et al. Zika virus in semen and spermatozoa. Lancet Infect. Dis. 16, 1106-1107 (2016).

73. Joguet, G. et al. Effect of acute Zika virus infection on sperm and virus clearance in body fluids: a prospective observational study. Lancet Infect. Dis. 17, 1200-1208 (2017).

74. Counotte, M. J. et al. Sexual transmission of Zika virus and other flaviviruses: a living systematic review. PLoS Med. 15, e1002611 (2018).
75. Maximova, O. A. \& Pletnev, A. G. Flaviviruses and the central nervous system: revisiting neuropathological concepts. Annu. Rev. Virol. 5, 255-272 (2018).

76. Cain, M. D., Salimi, H., Diamond, M. S. \& Klein, R. S. Mechanisms of pathogen invasion into the central nervous system. Neuron 103, 771-783 (2019).

77. Ludlow, M. et al. Neurotropic virus infections as the cause of immediate and delayed neuropathology. Acta Neuropathol. 131, 159-184 (2016).

78. Coyne, C. B. \& Lazear, H. M. Zika virus - reigniting the TORCH. Nat. Rev. Microbiol. 14, 707-715 (2016).

79. Platt, D. J. et al. Zika virus-related neurotropic flaviviruses infect human placental explants and cause fetal demise in mice. Sci. Transl. Med. 10, eaao7090 (2018).

80. Suthar, M. S., Diamond, M. S. \& Gale, M. Jr. West Nile virus infection and immunity. Nat. Rev. Microbiol. 11, 115-128 (2013).

81. Ngono, A. E. \& Shresta, S. Immune response to dengue and Zika. Annu. Rev. Immunol. 36, 279-308 (2018).

82. Ishikawa, H. \& Barber, G. N. STING is an endoplasmic reticulum adaptor that facilitates innate immune signalling. Nature 455, 674-678 (2008).

83. Maringer, K. \& Fernandez-Sesma, A. Message in a bottle: lessons learned from antagonism of STING signalling during RNA virus infection. Cytokine Growth Factor Rev. 25, 669-679 (2014).

84. McGuckin Wuertz, K. et al. STING is required for host defense against neuropathological West Nile virus infection. PLoS Pathog. 15, e1007899 (2019).

85. Schoggins, J. W. Recent advances in antiviral interferon-stimulated gene biology. F1000Res. 7, 309 (2018)

86. Schoggins, J. W. Interferon-stimulated genes: what do they all do? Annu. Rev. Virol. 6, 567-584 (2019).

87. Miorin, L., Maestre, A. M., Fernandez-Sesma, A. \& Garcia-Sastre, A. Antagonism of type I interferon by flaviviruses. Biochem. Biophys. Res. Commun. 492, 587-596 (2017).

88. Samuel, M. A. \& Diamond, M. S. Alpha/beta interferon protects against lethal West Nile virus infection by restricting cellular tropism and enhancing neuronal survival. J. Virol. 79, 13350-13361 (2005).

89. Lazear, H. M. et al. A mouse model of Zika virus pathogenesis. Cell Host Microbe 19, 720-730 (2016).

90. Lazear, H. M., Nice, T. J. \& Diamond, M. S. Interferon-lambda: immune functions at barrier surfaces and beyond. Immunity 43, 15-28 (2015).

91. Ma, D. et al. Antiviral effect of interferon lambda against West Nile virus. Antiviral Res. 83, 53-60 (2009).

92. Palma-Ocampo, H. K. et al. Interferon lambda inhibits dengue virus replication in epithelial cells. Virol. J. 12, 150 (2015).

93. Bayer, A. et al. Type III interferons produced by human placental trophoblasts confer protection against Zika virus infection. Cell Host Microbe 19, 705-712 (2016)

94. Chen, J. et al. Outcomes of congenital Zika disease depend on timing of infection and maternal-fetal interferon action. Cell Rep. 21, 1588-1599 (2017).

95. Jagger, B. W. et al. Gestational stage and IFN-lambda signaling regulate ZIKV infection in utero. Cell Host Microbe 22, 366-376 (2017).

96. Gorman, M. J., Poddar, S., Farzan, M. \& Diamond, M. S. The interferon-stimulated gene IFITM3 restricts West Nile virus infection and pathogenesis. J. Virol. 90, 8212-8225 (2016).

97. Lucas, T. M., Richner, J. M. \& Diamond, M. S. The interferon-stimulated gene Ifi27l $2 a$ restricts West Nile virus infection and pathogenesis in a cell-type- and region-specific manner. J. Virol. 90, 2600-2615 (2015).

98. Schoggins, J. W. Interferon-stimulated genes: roles in viral pathogenesis. Curr. Opin. Virol. 6, 40-46 (2014).

99. Li, C. et al. 25-Hydroxycholesterol protects host against Zika virus infection and its associated microcephaly in a mouse model. Immunity 46, 446-456 (2017).

100. Diamond, M. S. \& Farzan, M. The broad-spectrum antiviral functions of IFIT and IFITM proteins. Nat. Rev. Immunol. 13, 46-57 (2013).

101. Slon Campos, J. L., Mongkolsapaya, J. \& Screaton, G. R. The immune response against flaviviruses. Nat. Immunol. 19, 1189-1198 (2018).

102. Fernandez, E. et al. Mouse and human monoclonal antibodies protect against infection by multiple genotypes of Japanese encephalitis virus. mBio 9, e00008-18 (2018)

103. Williams, K. L. et al. Therapeutic efficacy of antibodies lacking Fc $\gamma$ receptor binding against lethal dengue virus infection is due to neutralizing potency and blocking of enhancing antibodies. PLoS Pathog. 9, e1003157 (2013).

104. Vogt, M. R. et al. Poorly neutralizing cross-reactive antibodies against the fusion loop of West Nile virus envelope protein protect in vivo via $\mathrm{Fc \gamma}$ receptor and complement-dependent effector mechanisms. J. Virol. 85, 11567-11580 (2011).

105. Bournazos, S., DiLillo, D. J. \& Ravetch, J. V. The role of $\mathrm{Fc}_{\mathrm{C}} \mathrm{F} \mathrm{F} \gamma \mathrm{R}$ interactions in IgG-mediated microbial neutralization. J. Exp. Med. 212, 1361-1369 (2015). 
106. Muller, D. A. \& Young, P. R. The flavivirus NS1 protein: molecular and structural biology, immunology, role in pathogenesis and application as a diagnostic biomarker. Antiviral Res. 98, 192-208 (2013).

107. Reyes-Sandoval, A. \& Ludert, J. E. The dual role of the antibody response against the flavivirus non-structural protein 1 (NS1) in protection and immuno-pathogenesis. Front. Immunol. 10, 1651 (2019).

108. Crill, W. D. \& Roehrig, J. T. Monoclonal antibodies that bind to domain III of dengue virus $\mathrm{E}$ glycoprotein are the most efficient blockers of virus adsorption to Vero cells. J. Virol. 75, 7769-7773 (2001).

109. Pierson, T. C., Fremont, D. H., Kuhn, R. J. \& Diamond, M. S. Structural insights into the mechanisms of antibody-mediated neutralization of flavivirus infection: implications for vaccine development. Cell Host Microbe 4, 229-238 (2008)

110. Rey, F. A., Stiasny, K., Vaney, M. C., Dellarole, M. \& Heinz, F. X. The bright and the dark side of human antibody responses to flaviviruses: lessons for vaccine design. EMBO Rep. 19, 206-224 (2018)

111. Katzelnick, L. C. et al. Antibody-dependent enhancement of severe dengue disease in humans. Science 358, 929-932 (2017).

112. Kliks, S. C., Nisalak, A., Brandt, W. E., Wahl, L. \& Burke, D. S. Antibody-dependent enhancement of dengue virus growth in human monocytes as a risk factor for dengue hemorrhagic fever. Am. J. Trop. Med. Hyg. 40, 444-451 (1989).

113. Netland, J. \& Bevan, M. J. CD8 and CD4 T cells in West Nile virus immunity and pathogenesis. Viruses 5, 2573-2584 (2013).

114. Weiskopf, D. \& Sette, A. T-cell immunity to infection with dengue virus in humans. Front. Immunol. 5, 93 (2014).

115. Aberle, J. H., Koblischke, M. \& Stiasny, K. CD4 T cell responses to flaviviruses. J. Clin. Virol. 108, 126-131 (2018).

116. Yauch, L. E. et al. CD4 ${ }^{+} \mathrm{T}$ cells are not required for the induction of dengue virus-specific $\mathrm{CD}^{+} \mathrm{T}$ cell or antibody responses but contribute to protection after vaccination. J. Immunol. 185, 5405-5416 (2010).

117. Kumar, P. et al. Impaired $T$ helper 1 function of nonstructural protein 3-specific T cells in Japanese patients with encephalitis with neurological sequelae. J. Infect. Dis. 189, 880-891 (2004).

118. Weiskopf, D. et al. Dengue virus infection elicits highly polarized CX3CR1 ${ }^{+}$ cytotoxic CD4 ${ }^{+} \mathrm{T}$ cells associated with protective immunity. Proc. Natl Acad. Sci. USA 112, E4256-4263 (2015).

119. Grifoni, A. et al. Prior dengue virus exposure shapes T cell immunity to Zika virus in humans. J. Virol. 91, e01469-17 (2017).

120. Beaumier, C. M. \& Rothman, A. L. Cross-reactive memory CD4 ${ }^{+}$T cells alter the $\mathrm{CD}^{+} \mathrm{T}$-cell response to heterologous secondary dengue virus infections in mice in a sequence-specific manner. Viral Immunol. 22, 215-219 (2009).

121. Elong Ngono, A. et al. Mapping and role of the $\mathrm{CD} 8^{+} \mathrm{T}$ cell response during primary Zika virus infection in mice. Cell Host Microbe 21, 35-46 (2017)

122. Brien, J. D., Uhrlaub, J. L. \& Nikolich-Zugich, J. Protective capacity and epitope specificity of $\mathrm{CD}^{+} \mathrm{T}$ cells responding to lethal West Nile virus infection. Eur. J. Immunol. 37, 1855-1863 (2007).

123. Yauch, L. E. et al. A protective role for dengue virus-specific $\mathrm{CD} 8^{+} \mathrm{T}$ cells. J. Immunol. 182, 4865-4873 (2009).

124. Shrestha, B. \& Diamond, M. S. Fas ligand interactions contribute to CD8 ${ }^{+}$ T-cell-mediated control of West Nile virus infection in the central nervous system. J. Virol. 81, 11749-11757 (2007).

125. Shrestha, B., Samuel, M. A. \& Diamond, M. S. CD ${ }^{+}$T cells require perforin to clear West Nile virus from infected neurons. J. Virol. 80 , 119-129 (2006).

126. Wen, J. et al. Identification of Zika virus epitopes reveals immunodominant and protective roles for dengue virus cross-reactive $\mathrm{CD}^{+} \mathrm{T}$ cells. Nat. Microbiol. 2, 17036 (2017).

127. Regla-Nava, J. A. et al. Cross-reactive Dengue virus-specific CD8 ${ }^{+} \mathrm{T}$ cells protect against Zika virus during pregnancy. Nat. Commun. 9, 3042 (2018).

128. Huang, $\mathrm{H}$. et al. $\mathrm{CD}^{+} \mathrm{T}$ cell immune response in immunocompetent mice during Zika virus infection. J. Virol. 91, e00900-17 (2017).

129. Jurado, K. A. et al. Antiviral CD8 T cells induce Zika-virus-associated paralysis in mice. Nat. Microbiol. 3, 141-147 (2018).

130. Ruzek, D. et al. CD8 ${ }^{+} \mathrm{T}$-cells mediate immunopathology in tick-borne encephalitis. Virology 384, 1-6 (2009).

131. Mongkolsapaya, J. et al. Original antigenic sin and apoptosis in the pathogenesis of dengue hemorrhagic fever. Nat. Med. 9, 921-927 (2003)

132. Mongkolsapaya, J. et al. T cell responses in dengue hemorrhagic fever: are cross-reactive T cells suboptimal? J. Immunol. 176, 3821-3829 (2006).

133. Bashyam, H. S., Green, S. \& Rothman, A. L. Dengue virus-reactive CD8 ${ }^{+}$ $\mathrm{T}$ cells display quantitative and qualitative differences in their response to variant epitopes of heterologous viral serotypes. J. Immunol. 176 2817-2824 (2006).

134. Mathew, A. \& Rothman, A. L. Understanding the contribution of cellular immunity to dengue disease pathogenesis. Immunol. Rev. 225 300-313 (2008).
135. Weiskopf, D. et al. Comprehensive analysis of dengue virus-specific responses supports an HLA-linked protective role for $\mathrm{CD}^{+} \mathrm{T}$ cells. Proc. Natl Acad. Sci. USA 110, E2046-E2053 (2013).

136. Anez, G., Heisey, D. A., Espina, L. M., Stramer, S. L. \& Rios, M. Phylogenetic analysis of dengue virus types 1 and 4 circulating in Puerto Rico and Key West, Florida, during 2010 epidemics. Am. J. Trop. Med. Hyg. 87, 548-553 (2012).

137. Centers for Disease Control and Prevention. Dengue hemorrhagic fever-U. S.-Mexico border, 2005. MMWR Morb. Mortal. Wkly Rep. 56, 785-789 (2007).

138. Halstead, S. B., Nimmannitya, S. \& Cohen, S. N. Observations related to pathogenesis of dengue hemorrhagic fever. IV. Relation of disease severity to antibody response and virus recovered. Yale J. Biol. Med. 42, 311-328 (1970).

139. Burke, D. S., Nisalak, A., Johnson, D. E. \& Scott, R. M. A prospective study of dengue infections in Bangkok. Am. J. Trop. Med. Hyg. 38, 172-180 (1988).

140. Halstead, S. B. Dengue. Lancet 370, 1644-1652 (2007).

141. Ngo, N. T. et al. Acute management of dengue shock syndrome: a randomized double-blind comparison of 4 intravenous fluid regimens in the first hour. Clin. Infect. Dis. 32, 204-213 (2001).

142. Graham, R. R. et al. A prospective seroepidemiologic study on dengue in children four to nine years of age in Yogyakarta, Indonesia I. studies in 1995-1996. Am. J. Trop. Med. Hyg. 61, 412-419 (1999).

143. Simmons, C. P. et al. Maternal antibody and viral factors in the pathogenesis of dengue virus in infants. J. Infect. Dis. 196, 416-424 (2007).

144. Hammond, S. N. et al. Differences in dengue severity in infants, children, and adults in a 3-year hospital-based study in Nicaragua. Am. J. Trop. Med. Hyg. 73, 1063-1070 (2005)

145. Kalayanarooj, S. \& Nimmannitya, S. Clinical presentations of dengue hemorrhagic fever in infants compared to children. J. Med. Assoc. Thai. 86 Suppl. 3, S673-S680 (2003).

146. Smithburn, K. C., Hughes, T. P., Burke, A. W. \& Paul, J. H. A neurotropic virus isolated from the blood of a native of Uganda. Am. J. Trop. Med. Hyg. 20, 471-492 (1940).

147. Higgs, S., Schneider, B. S., Vanlandingham, D. L., Klingler, K. A. \& Gould, E. A. Nonviremic transmission of West Nile virus. Proc. Natl Acad. Sci. USA 102, 8871-8874 (2005).

148. Hubalek, Z. \& Halouzka, J. West Nile fever - a reemerging mosquito-borne viral disease in Europe. Emerg. Inf. Dis. 5, 643-650 (1999).

149. West Nile Virus: Statistics \& Maps (Centers for Disease Control and Prevention, 2019); https://www.cdc.gov/westnile/statsmaps/index.html

150. Petersen, L. R. et al. Estimated cumulative incidence of West Nile virus infection in US adults, 1999-2010. Epidemiol. Infect. 141, 591-595 (2013).

151. Erdelyi, K. et al. Clinical and pathologic features of lineage 2 West Nile virus infections in birds of prey in Hungary. Vector Borne Zoonotic Dis. 7, 181-188 (2007)

152. Veo, C. et al. Evolutionary dynamics of the lineage 2 West Nile virus that caused the largest European epidemic: Italy 2011-2018. Viruses 11, 814 (2019).

153. Phipps, P., Johnson, N., McElhinney, L. M. \& Roberts, H. West Nile virus season in Europe. Vet. Rec. 183, 224 (2018).

154. Brault, A. C. et al. A single positively selected West Nile viral mutation confers increased virogenesis in American crows. Nat. Genet. 39, 1162-1166 (2007)

155. Tsai, T. F. New initiatives for the control of Japanese encephalitis by vaccination: minutes of a WHO/CVI meeting, Bangkok, Thailand, 13-15 October 1998. Vaccine 18 Suppl. 2, 1-25 (2000).

156. Solomon, T. Flavivirus encephalitis. N. Engl. J. Med. 351, 370-378 (2004).

157. Ooi, M. H. et al. The epidemiology, clinical features, and long-term prognosis of Japanese encephalitis in central Sarawak, Malaysia, 1997-2005. Clin. Infect. Dis. 47, 458-468 (2008).

158. Halstead, S. B. \& Thomas, S. J. New Japanese encephalitis vaccines: alternatives to production in mouse brain. Expert Rev. Vaccines 10, 355-364 (2011).

159. Hanna, J. N. et al. Japanese encephalitis in north Queensland, Australia, 1998. Med. J. Aust. 170, 533-536 (1999).

160. Simon-Loriere, E. et al. Autochthonous Japanese encephalitis with yellow fever coinfection in Africa. N. Engl. J. Med. 376, 1483-1485 (2017)

161. Mohammed, M. A. et al. Molecular phylogenetic and evolutionary analyses of Muar strain of Japanese encephalitis virus reveal it is the missing fifth genotype. Infect. Genet. Evol. 11, 855-862 (2011).

162. Kim, H. et al. Detection of Japanese encephalitis virus genotype V in Culex orientalis and Culex pipiens (Diptera: Culicidae) in Korea. PLoS ONE 10, $\mathrm{e} 0116547$ (2015).

163. $\mathrm{Li}, \mathrm{M}$. H. et al. Genotype V Japanese encephalitis virus is emerging. PLoS Negl. Trop. Dis. 5, e1231 (2011).

164. Connor, B. \& Bunn, W. B. The changing epidemiology of Japanese encephalitis and new data: the implications for new recommendations for Japanese encephalitis vaccine. Trop. Dis. Travel Med. Vaccines 3, 14 (2017). 
165. Huang, Y. J. et al. Susceptibility of a North American Culex quinquefasciatus to Japanese encephalitis virus. Vector Borne Zoonotic Dis. 15, 709-711 (2015).

166. Johansson, M. A., Vasconcelos, P. F. \& Staples, J. E. The whole iceberg: estimating the incidence of yellow fever virus infection from the number of severe cases. Trans. R. Soc. Trop. Med. Hyg. 108, 482-487 (2014).

167. Tuboi, S. H., Costa, Z. G., da Costa Vasconcelos, P. F. \& Hatch, D. Clinical and epidemiological characteristics of yellow fever in Brazil: analysis of reported cases 1998-2002. Trans. R. Soc. Trop. Med. Hyg. 101, 169-175 (2007).

168. Bryant, J. E., Holmes, E. C. \& Barrett, A. D. Out of Africa: a molecular perspective on the introduction of yellow fever virus into the Americas. PLoS Pathog. 3, e75 (2007).

169. Barrett, A. D. \& Higgs, S. Yellow fever: a disease that has yet to be conquered. Annu. Rev. Entomol. 52, 209-229 (2007).

170. Garske, T. et al. Yellow fever in Africa: estimating the burden of disease and impact of mass vaccination from outbreak and serological data. PLoS Med. 11, e1001638 (2014).

171. Hamlet, A. et al. The seasonal influence of climate and environment on yellow fever transmission across Africa. PLoS. Negl. Trop. Dis. 12, e0006284 (2018)

172. Hamer, D. H. et al. Fatal yellow fever in travelers to Brazil, 2018. MMWR Morb. Mortal. Wkly Rep. 67, 340-341 (2018).

173. Rezende, I. M. et al. Persistence of yellow fever virus outside the Amazon basin, causing epidemics in Southeast Brazil, from 2016 to 2018. PLoS Negl. Trop. Dis. 12, e0006538 (2018).

174. Metsky, H. C. et al. Zika virus evolution and spread in the Americas. Nature 546, 411-415 (2017).

175. Musso, D. et al. Zika virus in French Polynesia 2013-14: anatomy of a completed outbreak. Lancet Infect. Dis. 18, e172-e182 (2018).

176. Mlakar, J. et al. Zika virus associated with microcephaly. N. Engl. J. Med. 374, 951-958 (2016).

177. Ali, S. et al. Environmental and social change drive the explosive emergence of Zika virus in the Americas. PLoS Negl. Trop. Dis. 11, e0005135 (2017).

178. Liu, Y. et al. Evolutionary enhancement of Zika virus infectivity in Aedes aegypti mosquitoes. Nature 545, 482-486 (2017).

179. Faria, N. R. et al. Zika virus in the Americas: early epidemiological and genetic findings. Science 352, 345-349 (2016).

180. Yuan, L. et al. A single mutation in the prM protein of Zika virus contributes to fetal microcephaly. Science 358, 933-936 (2017).

181. Watanabe, S., Tan, N. W. W., Chan, K. W. K. \& Vasudevan, S. G. Dengue virus and Zika virus serological cross-reactivity and their impact on pathogenesis in mice. J. Infect. Dis. 219, 223-233 (2019).

182. Klase, Z. A. et al. Zika fetal neuropathogenesis: etiology of a viral syndrome. PLoS Negl. Trop. Dis. 10, e0004877 (2016).

183. Chavali, P. L. et al. Neurodevelopmental protein Musashi-1 interacts with the Zika genome and promotes viral replication. Science 357, 83-88 (2017)

184. Xia, H. et al. An evolutionary NS1 mutation enhances Zika virus evasion of host interferon induction. Nat. Commun. 9, 414 (2018).

185. Dejnirattisai, W. et al. Dengue virus sero-cross-reactivity drives antibody-dependent enhancement of infection with zika virus. Nat. Immunol. 17, 1102-1108 (2016).

186. Li, M. et al. Dengue immune sera enhance Zika virus infection in human peripheral blood monocytes through Fc gamma receptors. PLoS ONE 13, e0200478 (2018).

187. Halstead, S. B. Biologic evidence required for Zika disease enhancement by dengue antibodies. Emerg. Infect. Dis. 23, 569-573 (2017).

188. Fernandez, E. et al. Human antibodies to the dengue virus E-dimer epitope have therapeutic activity against Zika virus infection. Nat. Immunol. 18, 1261-1269 (2017).

189. Abbink, P. et al. Therapeutic and protective efficacy of a dengue antibody against Zika infection in rhesus monkeys. Nat. Med. 24, 721-723 (2018).

190. Bardina, S. V. et al. Enhancement of Zika virus pathogenesis by preexisting antiflavivirus immunity. Science 356, 175-180 (2017).

191. Duehr, J. et al. Tick-borne encephalitis virus vaccine-induced human antibodies mediate negligible enhancement of Zika virus infection in vitro and in a mouse model. mSphere 3, e00011-18 (2018).

192. Wen, J. et al. Dengue virus-reactive $\mathrm{CD}^{+} \mathrm{T}$ cells mediate cross-protection against subsequent Zika virus challenge. Nat. Commun. 8, 1459 (2017).

193. McCracken, M. K. et al. Impact of prior flavivirus immunity on Zika virus infection in rhesus macaques. PLoS Pathog. 13, e1006487 (2017).

194. Pantoja, P. et al. Zika virus pathogenesis in rhesus macaques is unaffected by pre-existing immunity to dengue virus. Nat. Commun. 8, 15674 (2017).

195. Breitbach, M. E. et al. Primary infection with dengue or Zika virus does not affect the severity of heterologous secondary infection in macaques. PLoS Pathog. 15, e1007766 (2019).

196. George, J. et al. Prior exposure to Zika virus significantly enhances peak dengue-2 viremia in rhesus macaques. Sci. Rep. 7, 10498 (2017).

197. Valiant, W. G. et al. Zika convalescent macaques display delayed induction of anamnestic cross-neutralizing antibody responses after dengue infection. Emerg. Microbes Infect. 7, 130 (2018).
198. Terzian, A. C. B. et al. Viral load and cytokine response profile does not support antibody-dependent enhancement in dengue-primed Zika virus-infected patients. Clin. Infect. Dis. 65, 1260-1265 (2017).

199. Halai, U. A. et al. Maternal Zika virus disease severity, virus load, prior dengue antibodies, and their relationship to birth outcomes. Clin. Infect. Dis. 65, 877-883 (2017).

200. Draper, C. C. Infection with the Chuku strain of Spondweni virus. West Afr Med. J. 14, 16-19 (1965).

201. Kokernot, R. H., Smithburn, K. C., Muspratt, J. \& Hodgson, B. Studies on arthropod-borne viruses of Tongaland. VIII. Spondweni virus, an agent previously unknown, isolated from Taeniorhynchus (Mansonioides) uniformis. S. Afr. J. Med. Sci. 22, 103-112 (1957).

202. Haddow, A. D. \& Woodall, J. P. Distinguishing between Zika and Spondweni viruses. Bull. World Health Organ. 94, 711-711A (2016).

203. Haddow, A. D. et al. Genetic characterization of Spondweni and Zika viruses and susceptibility of geographically distinct strains of Aedes aegypti, Aedes albopictus and Culex quinquefasciatus (Diptera: Culicidae) to Spondweni virus. PLoS Negl. Trop. Dis. 10, e0005083 (2016).

204. White, S. K., Lednicky, J. A., Okech, B. A., Morris, J. G. Jr \& Dunford, J. C. Spondweni virus in field-caught Culex quinquefasciatus mosquitoes, Haiti, 2016. Emerg. Infect. Dis. 24, 1765-1767 (2018).

205. McDonald, E. M., Duggal, N. K. \& Brault, A. C. Pathogenesis and sexual transmission of Spondweni and Zika viruses. PLoS Negl. Trop. Dis. 11, e0005990 (2017)

206. Engel, D. et al. Reconstruction of the evolutionary history and dispersal of Usutu virus, a neglected emerging arbovirus in Europe and Africa. mBio 7, e01938-15 (2016).

207. Barzon, L. Ongoing and emerging arbovirus threats in Europe. J. Clin. Virol. 107, 38-47 (2018).

208. Weissenbock, H. et al. Emergence of Usutu virus, an African mosquito-borne flavivirus of the Japanese encephalitis virus group, central Europe. Emerg. Infect. Dis. 8, 652-656 (2002).

209. Cadar, D. et al. Widespread activity of multiple lineages of Usutu virus, western Europe, 2016. Euro. Surveill. 22, 30452 (2017).

210. Pierro, A. et al. Detection of specific antibodies against West Nile and Usutu viruses in healthy blood donors in northern Italy, 2010-2011. Clin. Microbiol. Infect. 19, E451-E453 (2013).

211. Gaibani, P. \& Rossini, G. An overview of Usutu virus. Microbes Infect. 19, 382-387 (2017).

212. Pauvolid-Correa, A. et al. Ilheus virus isolation in the Pantanal, west-central Brazil. PLoS Negl. Trop. Dis. 7, e2318 (2013).

213. Weyer, J. et al. Human cases of Wesselsbron disease, South Africa 2010-2011. Vector Borne Zoonotic Dis. 13, 330-336 (2013).

214. Pauvolid-Correa, A. et al. Neutralising antibodies for West Nile virus in horses from Brazilian Pantanal. Mem. Inst. Oswaldo Cruz 106, 467-474 (2011)

215. Vieira, C. et al. Detection of Ilheus virus in mosquitoes from southeast Amazon, Brazil. Trans. R. Soc. Trop. Med. Hyg. 113, 424-427 (2019).

216. de Souza Lopes, O., Coimbra, T. L., de Abreu Sacchetta, L. \& Calisher, C. $\mathrm{H}$. Emergence of a new arbovirus disease in Brazil. I. Isolation and characterization of the etiologic agent, Rocio virus. Am. J. Epidemiol. 107, 444-449 (1978).

217. Medeiros, D. B., Nunes, M. R., Vasconcelos, P. F., Chang, G. J. \& Kuno, G. Complete genome characterization of Rocio virus (Flavivirus: Flaviviridae), a Brazilian flavivirus isolated from a fatal case of encephalitis during an epidemic in Sao Paulo state. J. Gen. Virol. 88, 2237-2246 (2007).

218. Mitchell, C. J., Monath, T. P. \& Cropp, C. B. Experimental transmission of Rocio virus by mosquitoes. Am. J. Trop. Med. Hyg. 30, 465-472 (1981).

219. Monath, T. P., Kemp, G. E., Cropp, C. B. \& Bowen, G. S. Experimental infection of house sparrows (Passer domesticus) with Rocio virus. Am. J. Trop. Med. Hyg. 27, 1251-1254 (1978).

220. Pauvolid-Correa, A. et al. Serological evidence of widespread circulation of West Nile virus and other flaviviruses in equines of the Pantanal, Brazil. PLoS Negl. Trop. Dis. 8, e2706 (2014).

221. Straatmann, A. et al. Serological evidence of the circulation of the Rocio arbovirus (Flaviviridae) in Bahia]. Rev. Soc. Bras. Med. Tro. 30, 511-515 (1997)

222. Diagne, M. M. et al. Emergence of Wesselsbron virus among black rat and humans in Eastern Senegal in 2013. One Health 3, 23-28 (2017).

223. Gritsun, T. S., Nuttall, P. A. \& Gould, E. A. Tick-borne flaviviruses. Adv. Virus Res. 61, 317-371 (2003).

224. Kemenesi, G. \& Banyai, K. Tick-borne flaviviruses, with a focus on Powassan virus. Clin. Microbiol. Rev. 32, e00106-17 (2019).

225. Hermance, M. E. \& Thangamani, S. Powassan virus: an emerging arbovirus of public health concern in North America. Vector Borne Zoonotic Dis. 17, 453-462 (2017).

226. Ebel, G. D., Spielman, A. \& Telford, S. R. III Phylogeny of North American Powassan virus. J. Gen. Virol. 82, 1657-1665 (2001). 
227. Dupuis, A. P. II et al. Isolation of deer tick virus (Powassan virus, lineage II) from Ixodes scapularis and detection of antibody in vertebrate hosts sampled in the Hudson Valley, New York State. Parasit. Vectors 6, 185 (2013).

228. Montgomery, R. R. \& Murray, K. O. Risk factors for West Nile virus infection and disease in populations and individuals. Expert Rev. Anti Infect. Ther. 13, 317-325 (2015).

229. Krow-Lucal, E. R., Lindsey, N. P., Fischer, M. \& Hills, S. L. Powassan virus disease in the United States, 2006-2016. Vector Borne Zoonotic Dis. 18, 286-290 (2018).

230. Aliota, M. T. et al. The prevalence of zoonotic tick-borne pathogens in Ixodes scapularis collected in the Hudson Valley, New York State. Vector Borne Zoonotic Dis. 14, 245-250 (2014).

231. Knox, K. K. et al. Powassan/deer tick virus and Borrelia burgdorferi infection in Wisconsin tick populations. Vector Borne Zoonotic Dis. 17, 463-466 (2017).

232. Eisen, R. J. \& Eisen, L. The blacklegged tick, Ixodes scapularis: an increasing public health concern. Trends Parasitol. 34, 295-309 (2018).

233. VanBlargan, L. A. et al. An mRNA vaccine protects mice against multiple tick-transmitted flavivirus infections. Cell Rep. 25, 3382-3392 (2018).

234. Gardner, C. L. \& Ryman, K. D. Yellow fever: a reemerging threat. Clin. Lab. Med. 30, 237-260 (2010)

235. Halstead, S. B. \& Jacobson, J. in Vaccines (eds Plotkin, S.A., Orenstein, W. A. et al.) 311-352 (Saunders, 2008).

236. Huang, C. Y. et al. Chimeric dengue type 2 (vaccine strain PDK-53)/dengue type 1 virus as a potential candidate dengue type 1 virus vaccine. J. Virol. 74, 3020-3028 (2000).

237. Huang, C. Y. et al. Dengue 2 PDK-53 virus as a chimeric carrier for tetravalent dengue vaccine development. J. Virol. 77, 11436-11447 (2003).

238. Guy, B. et al. Preclinical and clinical development of YFV 17D-based chimeric vaccines against dengue, West Nile and Japanese encephalitis viruses. Vaccine 28, 632-649 (2010).

239. Guirakhoo, F. et al. Construction, safety, and immunogenicity in nonhuman primates of a chimeric yellow fever-dengue virus tetravalent vaccine. J. Virol. 75, 7290-7304 (2001).

240. Whitehead, S. S. Development of TV003/TV005, a single dose, highly immunogenic live attenuated dengue vaccine; what makes this vaccine different from the Sanofi-Pasteur CYD vaccine? Expert Rev. Vaccines 15, 509-517 (2016).

241. Appaiahgari, M. B. \& Vrati, S. IMOJEV $\left({ }^{\star}\right)$ : a Yellow fever virus-based novel Japanese encephalitis vaccine. Expert Rev. Vaccines 9, 1371-1384 (2010).

242. Zust, R. et al. Rational design of a live attenuated dengue vaccine: 2 '-o-methyltransferase mutants are highly attenuated and immunogenic in mice and macaques. PLoS Pathog. 9, e1003521 (2013).

243. Richner, J. M. et al. Vaccine mediated protection against Zika virus-induced congenital disease. Cell 170, 273-283 (2017).

244. Fischer, M., Lindsey, N., Staples, J. E. \& Hills, S. Japanese encephalitis vaccines: recommendations of the Advisory Committee on Immunization Practices (ACIP). MMWR Recomm. Rep. 59, 1-27 (2010).

245. Rendi-Wagner, P. Advances in vaccination against tick-borne encephalitis. Expert Rev. Vaccines 7, 589-596 (2008).

246. Kasabi, G. S. et al. Coverage and effectiveness of Kyasanur forest disease (KFD) vaccine in Karnataka, South India, 2005-10. PLoS Negl. Trop. Dis. 7, e2025 (2013).

247. Hadinegoro, S. R. et al. Efficacy and long-term safety of a dengue vaccine in regions of endemic disease. N. Engl. J. Med. 373, 1195-1206 (2015).

248. Addendum to report of the Global Advisory Committee on Vaccine Safety (GACVS), 10-11 June 2015. Safety of CYD-TDV dengue vaccine. Wkly Epidemiol Rec. 90, 421-423 (2015).

249. Sridhar, S. et al. Effect of dengue serostatus on dengue vaccine safety and efficacy. N. Engl. J. Med. 379, 327-340 (2018).

250. Halstead, S. B. Dengvaxia sensitizes seronegatives to vaccine enhanced disease regardless of age. Vaccine 35, 6355-6358 (2017).

251. Biswal, S. et al. Efficacy of a tetravalent dengue vaccine in healthy children and adolescents. N. Engl. J. Med. 381, 2009-2019 (2019).

252. Whitehead, S. S. et al. In a randomized trial, the live attenuated tetravalent dengue vaccine TV003 is well-tolerated and highly immunogenic in subjects with flavivirus exposure prior to vaccination. PLoS Negl. Trop. Dis. 11, e0005584 (2017)

253. Collins, M. H. et al. Lack of durable cross-neutralizing antibodies against Zika virus from dengue virus infection. Emerg. Infect. Dis. 23, 773-781 (2017).

254. Montoya, M. et al. Longitudinal analysis of antibody cross-neutralization following Zika virus and dengue virus infection in Asia and the Americas. J. Infect. Dis. 218, 536-545 (2018).

255. Balmaseda, A. et al. Antibody-based assay discriminates Zika virus infection from other flaviviruses. Proc. Natl Acad. Sci. USA 114, 8384-8389 (2017).

256. Lindsey, N. P. et al. Ability to serologically confirm recent Zika virus infection in areas with varying past incidence of dengue virus infection in the United States and U.S. territories in 2016. J. Clin. Microbiol. 56, e01115-17 (2017).
257. Richner, J. M. et al. Modified mRNA vaccines protect against Zika virus infection. Cell 168, 1114-1125 (2017).

258. Diamond, M. S., Ledgerwood, J. E. \& Pierson, T. C. Zika virus vaccine development: progress in the face of new challenges. Annu. Rev. Med. 70, 121-135 (2019).

259. Casey, R. M. et al. Immunogenicity of fractional-dose vaccine during a yellow fever outbreak - final report. N. Engl. J. Med. 381, 444-454 (2019).

260. Eyer, L., Nencka, R., de Clercq, E., Seley-Radtke, K. \& Ruzek, D. Nucleoside analogs as a rich source of antiviral agents active against arthropod-borne flaviviruses. Antivir. Chem. Chemother. 26, 1-28 (2018).

261. Niyomrattanakit, P. et al. Inhibition of dengue virus polymerase by blocking of the RNA tunnel. J. Virol. 84, 5678-5686 (2010).

262. Chen, Y. L., Yokokawa, F. \& Shi, P. Y. The search for nucleoside/nucleotide analog inhibitors of dengue virus. Antiviral Res. 122, 12-19 (2015).

263. Warren, T. K. et al. Protection against filovirus diseases by a novel broad-spectrum nucleoside analogue BCX4430. Nature 508, 402-405 (2014).

264. Julander, J. G. et al. Efficacy of the broad-spectrum antiviral compound BCX4430 against Zika virus in cell culture and in a mouse model. Antiviral Res. 137, 14-22 (2017).

265. Bullard-Feibelman, K. M. et al. The FDA-approved drug sofosbuvir inhibits Zika virus infection. Antiviral Res. 137, 134-140 (2017).

266. Dong, H., Zhang, B. \& Shi, P. Y. Flavivirus methyltransferase: a novel antiviral target. Antiviral Res. 80, 1-10 (2008).

267. Lim, S. P. et al. Small molecule inhibitors that selectively block dengue virus methyltransferase. J. Biol. Chem. 286, 6233-6240 (2011).

268. Majerova, T., Novotny, P., Krysova, E. \& Konvalinka, J. Exploiting the unique features of Zika and dengue proteases for inhibitor design. Biochimie 166, 132-141 (2019).

269. Nitsche, C. Strategies towards protease inhibitors for emerging flaviviruses. Adv. Exp. Med. Biol. 1062, 175-186 (2018).

270. Li, Z. et al. Existing drugs as broad-spectrum and potent inhibitors for Zika virus by targeting NS2B-NS3 interaction. Cell Res. 27, 1046-1064 (2017)

271. Yuan, S. et al. Structure-based discovery of clinically approved drugs as Zika virus NS2B-NS3 protease inhibitors that potently inhibit Zika virus infection in vitro and in vivo. Antiviral Res. 145, 33-43 (2017).

272. Luo, D., Vasudevan, S. G. \& Lescar, J. The flavivirus NS2B-NS3 protease-helicase as a target for antiviral drug development. Antiviral Res. 118, 148-158 (2015)

273. Modis, Y., Ogata, S., Clements, D. \& Harrison, S. C. A ligand-binding pocket in the dengue virus envelope glycoprotein. Proc. Natl Acad. Sci. USA 100, 6986-6991 (2003).

274. Poh, M. K. et al. A small molecule fusion inhibitor of dengue virus. Antiviral Res. 84, 260-266 (2009).

275. Schmidt, A. G., Lee, K., Yang, P. L. \& Harrison, S. C. Small-molecule inhibitors of dengue-virus entry. PLoS Pathog. 8, e1002627 (2012).

276. Schmidt, A. G., Yang, P. L. \& Harrison, S. C. Peptide inhibitors of flavivirus entry derived from the E protein stem. J. Virol. 84, 12549-12554 (2010).

277. Schmidt, A. G., Yang, P. L. \& Harrison, S. C. Peptide inhibitors of dengue-virus entry target a late-stage fusion intermediate. PLoS Pathog. 6, e1000851 (2010)

278. Byrd, C. M. et al. A novel inhibitor of dengue virus replication that targets the capsid protein. Antimicrob. Agents Chemother. 57, 15-25 (2013)

279. Scaturro, P. et al. Characterization of the mode of action of a potent dengue virus capsid inhibitor. J. Virol. 88, 11540-11555 (2014).

280. Smith, J. L. et al. Characterization and structure-activity relationship analysis of a class of antiviral compounds that directly bind dengue virus capsid protein and are incorporated into virions. Antiviral Res. $\mathbf{1 5 5}$ 12-19 (2018).

281. Shaw, W. R. \& Catteruccia, F. Vector biology meets disease control: using basic research to fight vector-borne diseases. Nat. Microbiol. 4, 20-34 (2019).

282. Moreira, L. A. et al. A Wolbachia symbiont in Aedes aegypti limits infection with dengue, Chikungunya, and Plasmodium. Cell 139, 1268-1278 (2009)

283. Dutra, H. L. et al. Wolbachia blocks currently circulating Zika virus isolates in Brazilian Aedes aegypti mosquitoes. Cell Host Microbe 19, 771-774 (2016).

284. Carrington, L. B. et al. Field- and clinically derived estimates of Wolbachia-mediated blocking of dengue virus transmission potential in Aedes aegypti mosquitoes. Proc. Natl Acad. Sci. USA 115, 361-366 (2018).

285. Thomas, S., Verma, J., Woolfit, M. \& O’Neill, S. L. Wolbachia-mediated virus blocking in mosquito cells is dependent on XRN1-mediated viral RNA degradation and influenced by viral replication rate. PLoS Pathog. 14 e1006879 (2018)

286. Ferguson, N. M. et al. Modeling the impact on virus transmission of Wolbachia-mediated blocking of dengue virus infection of Aedes aegypti. Sci. Transl. Med. 7, 279 ra237 (2015). 
287. Hoffmann, A. A. et al. Stability of the $w$ Mel Wolbachia infection following invasion into Aedes aegypti populations. PLoS Negl. Trop. Dis. 8, e3115 (2014).

288. Anders, K. L. et al. The AWED trial (Applying Wolbachia to Eliminate Dengue) to assess the efficacy of Wolbachia-infected mosquito deployments to reduce dengue incidence in Yogyakarta, Indonesia: study protocol for a cluster randomised controlled trial. Trials 19, 302 (2018).

289. Franz, A. W. et al. Fitness impact and stability of a transgene conferring resistance to dengue-2 virus following introgression into a genetically diverse Aedes aegypti strain. PLoS Negl. Trop. Dis. 8, e2833 (2014).

290. Buchman, A. et al. Engineered resistance to Zika virus in transgenic Aedes aegypti expressing a polycistronic cluster of synthetic small RNAs. Proc. Natl Acad. Sci. USA 116, 3656-3661 (2019).

291. Hadler, J. L. et al. Assessment of arbovirus surveillance 13 years after introduction of West Nile virus, United States. Emerg. Infect. Dis. 21, 1159-1166 (2015).

292. Kose, N. et al. A lipid-encapsulated mRNA encoding a potently neutralizing human monoclonal antibody protects against chikungunya infection. Sci. Immunol. 4, eaaw6647 (2019).

\section{Acknowledgements}

This work is dedicated to the memory of Dr Michael Rossmann (1930-2019), who pioneered our structural understanding of flaviviruses and their interactions with the host. This work was supported by the intramural program of the National Institute of Allergy and Infectious Diseases and the National Institutes of Health (NIH; grant nos. R01 AI073755, R01 AI127828 and R01 HD091218 to M.S.D). We thank Ethan Tyler (NIH Office of the Director) for preparation of the figures. We also thank N. Vasilakis and S. Weaver for their editorial comments.

\section{Author contributions}

T.C.P. and M.S.D. conceived the review, wrote the first draft and edited the manuscript into its final form.

\section{Competing interests}

M.S.D. is a consultant for Inbios, is on the Scientific Advisory Board of Moderna and also receives funding from Emergent BioSolutions. The remaining author declares no competing interests.

\section{Additional information}

Correspondence should be addressed to T.C.P. or M.S.D.

Reprints and permissions information is available at www.nature.com/reprints. Publisher's note Springer Nature remains neutral with regard to jurisdictional claims in published maps and institutional affiliations.

(C) Springer Nature Limited 2020 